\title{
Sobre el origen y desarrollo de la conciencia política del movimiento estudiantil universitario chileno. De su conciencia anarquista a su antineoliberalismo. 1906-2012 \\ About the origin and development of the political consciousness of the Chilean college students movement. From its anarchist consciousness to its antineoliberalism. 1906-2012
}

Gabriel Rivas Castro

Consejo Nacional de Investigaciones Científicas y Técnicas (CONICET), Universidad Nacional de General Sarmiento (UNGS), girc1984@gmail.com

Tamara Seiffer

Consejo Nacional de Investigaciones Científicas y Técnicas (CONICET), Universidad de Buenos Aires, (UBA), seiffertamara@gmail.com

\section{Historia editorial Resumen}

Recibido: [15/11/2021]

Primera revisión: [3/12/2021]

Aceptado: [12/12/2021]

Publicado: [27/12/2021]

\section{Palabras clave}

Conflicto político;

Movimiento estudiantil; Política educacional;

Capitalismo; Chile
El movimiento estudiantil chileno se impuso como un actor político de peso. En 2011, fue protagonista de la expresión más masiva y sostenida de una huelga política desde el fin de la dictadura, cuyas repercusiones siguen hasta la fecha. En el presente trabajo buscamos explicar la necesidad social de la acción política de este movimiento. Anclados en los desarrollos críticos a la economía política iniciados por Marx y Engels, avanzaremos por tres ciclos de la lucha de clases durante los cuales la conciencia política de las direcciones estudiantiles ha tenido distintas formas. Partiendo de entender a la conciencia como modo del ser social, esperamos contribuir al conocimiento objetivo de las formas aludidas como punto de partida para comprender las actuales determinaciones y potencias de la acción política de la clase obrera en Chile.

\section{Abstract}

\section{Keywords}

Political conflict; Student movement; Educative politics; Capitalism; Chile
The Chilean student movement imposed itself as an important political actor. In 2011, it was a lead character in the most massive and sustained political strike since the end of the dictatorship, which repercussions continues until this date. In this paper, we will seek to explain the social necessity for the political action of this movement Anchored in the critical developments to political economy initiated by Marx and Engels, we will go through three cycles of class struggle during which the political consciousness of the student leaderships has taken different forms. Starting from understanding consciousness as a mode of social being, we hope to make a contribution to the objective knowledge of the aforementioned forms as a starting point to comprehend the current determinations and powers of the political action of the Chilean working class 


\section{Introducción}

El movimiento estudiantil chileno se ha destacado como actor político durante todo el siglo XX y lo que llevamos del XXI. No sólo por su masividad, sino porque logró aunar un conjunto de demandas sociales al punto que para algunos autores podría considerarse en sí mismo un partido (Braghetto, 2013). En el 2011, su inédita masividad e impacto político le dieron fama internacional. Esto ha inspirado una serie de trabajos que buscan rastrear su trayectoria y los elementos que lo han transformado en un sujeto capaz de anteponerse a lo que comúnmente se ha llamado "neoliberalismo" de un modo mucho más organizado que el sindicalismo o algunas expresiones territoriales. Sin embargo, al momento de dar cuenta qué es lo que determina la necesidad de su acción no se avanza mucho más.

Están quienes lo ven como expresión de un abstracto "poder constituyente" (Zepeda, 2014) explicado por la incapacidad de la élite política para llevar adelante las transformaciones sociales en juego (Sotomayor, 2019). También hay quienes plantean que viene a realizar la democracia truncada que genera una crisis de legitimidad, con la perspectiva de destrabar los "enclaves autoritarios" (Garretón et al, 2011; Garcés, 2013) o levantar formas de democracia todavía más radicales (Agacino, 2013). Otros autores lo entienden como el promotor de la equidad y la mejora de la educación contra su mercantilización (Oyarzún, 2012; Rubilar, 2011), o bien que se contrapone al orden social elitista (De la Cuadra, 2008). Algunos lo miran como el sujeto del "desarrollo" pendiente (Cañas, 2016), reconstructor de la acción colectiva (Donoso, 2014) o productor de una "nueva lógica" liberal para reordenar el mundo universitario (Donoso, 2020). Otros argumentan que es el modo de ampliar el control reflexivo de "la nueva clase media" por medios administrativos (Fleet, 2011) o dinamizador de un proceso post-transicional (Rifo, 2013). Este conjunto de visiones que observan qué dice el movimiento 
estudiantil de sí mismo y sus efectos inmediatos, se limita a señalar una supuesta potencia política sin dar cuenta de la necesidad que la determina como forma de la conciencia del mismo sujeto. De esta forma confunde lo que dice la dirección estudiantil inmediatamente sobre sí misma con lo que efectivamente es, invirtiendo el hecho de que su "posición práctica en la vida" (Marx y Engels, 1968: 55) es lo que explica sus ideas y no sus ideas su posición práctica.

Otro grupo de autores, impulsados por la necesidad de avanzar sobre el contenido de las formas conscientes, se fijan en las transformaciones que repercuten en las determinaciones de clase del estudiantado y sus direcciones políticas (Orellana, 2011; Ruiz y Boccardo, 2015; Thielemann, 2016) o en el vínculo específico que los estudiantes desarrollan con las instituciones políticas del Estado (Muñoz y Durán, 2019). En el primer grupo de autores, el conjunto de transformaciones materiales aparece como el producto de una acción ideal previa: el modelo neoliberal implementado por la dictadura. En el segundo, no se irá más allá de la conciencia contrapuesta a las instituciones estatales en general, reduciendo su conciencia política a ser el reflejo de la acción de una institución estatal que, por ser "política", "politiza" al sujeto que se le enfrenta. Ninguno de estos desarrollos explica ni el contenido económico de dicha conciencia ni el modo ideal bajo el cual la vida material resuelve sus contradicciones, que es lo que nos interesa relevar. ${ }^{1}$ Por ello planteamos que no logran presentar un desarrollo unitario donde sea posible ver la conexión interna entre la organización de la vida material y el modo consciente

${ }^{1}$ Como aclaración, considerando que nuestro esfuerzo escapa a lo hecho por la bibliografía citada, entrar en una exposición de matices y diferencias de la misma implica un desarrollo extenso que reduciría excesivamente nuestra contribución. Queda, por tanto, pendiente un examen más detallado de los problemas y aciertos de la bibliografía existente.

\section{๑}

ANUARI DEL CONFLICTE SOCIAL, 12 
de realizarla, por lo que economía y política quedan, finalmente, separadas.

Apoyados en la crítica a la economía política inaugurada por Marx, ${ }^{2}$ este artículo se propone mostrar cómo la conciencia política del movimiento estudiantil -expresada en sus direcciones-, es un atributo que se encuentra determinado como la forma concreta de una necesidad social general de carácter antagónico. Esto quiere decir que no basta para comprender lo que determina la forma de la conciencia política de las direcciones estudiantiles el describir lo que ellas dicen de sí mismas, cómo la conciben sus antagonistas o como un sujeto que se organiza en torno a una cadena de significantes (Laclau y Mouffe, 1987), simplemente, sin explicar la necesidad de su carácter cualitativo. Desde nuestro punto de vista, la explicación sobre la forma concreta de la conciencia política del movimiento estudiantil objetivada para sí mismo como una serie de direcciones en disputa, implica superar su consideración abstracta como una conciencia simplemente libre y ponerla en unidad de su relación social. Ésta se les impone a los sujetos como su propia acción que, libre de todo vínculo de dependencia personal y mediada por los productos del trabajo privado, desencadena la serie de vínculos recíprocos que organizan la unidad del trabajo social. En otras palabras, buscamos mostrar que la conciencia política del movimiento estudiantil, expresada en su dirección política y objetivada en las instituciones y discursos que lo determinan como sujeto de su propia actividad, es el modo consciente y voluntario de realizar una necesidad social enajenada en los

2 Existen trabajos que, compartiendo nuestro punto de partida, han mirado cuestiones relacionadas con lo que desarrollamos. A todos los tenemos en consideración en nuestro propio desarrollo. Entre ellos, sobre la formación del sistema educativo y el ser social estudiantil se puede consultar Hirsch e Iñigo (2005) e Iñigo Carrera (2013).

\section{(U)}

ANUARI DEL CONFLICTE SOCIAL, 12 
productos del trabajo. ${ }^{3}$ Considerando a la conciencia como una forma determinada del ser social, compartimos la observación de Marx en su prólogo a la Contribución a la Crítica de la Economía Política, para quien "no es la conciencia de los hombres lo que determina su ser, sino, por el contrario, es su existencia social lo que determina su conciencia" (Marx, 2011, p. 5). Al ser la premisa de toda vida humana su reproducción en tanto sujetos vivos por medio de la producción de sus medios de vida y por ser su propia reproducción como género una necesidad vital, la conciencia -y con ella el lenguaje y todo lo que refiere a su organización consciente de la vida social- surge como una determinada forma del ser social o como el ser social consciente (Marx y Engels, 1968, p. 22). Es decir, la conciencia emerge portando, como determinación abstracta, el conjunto de relaciones sociales materiales que le dan origen como forma de organización de la vida material en un momento determinado de su historia. ${ }^{4}$

${ }^{3}$ Sobre la determinación de la conciencia por el ser social, ver: Marx (2011), Marx y Engels, (1968), Tran Duc Thao (2020 y 1971) e Iñigo Carrera (2007 y 2013a).

${ }^{4}$ Sobre esta cuestión el marxismo tiene una larga tradición de posiciones. Después de la muerte de Marx, encontramos autores como Plejanov (1964) Lenin (1969) y Kautsky (1979), quienes conciben a la conciencia como económicamente determinada o forma de una determinación económica y a la misma clase obrera como portadora de su potencia histórica, lo que la determina como sujeto revolucionario. Luego, otros autores como Lukács (2013), Rubin (1990), Sohn Rethel (2017) y Tran Duc Thao (1971, 2020), con diferentes grados de acierto, profundizaron los estudios sobre los modos en que la forma mercancía determina la conciencia del productor privado, incluyendo a la clase obrera. Tradición que se extiende a autores como Backhaus (1978), De Vroey $(1988)$ y Clarke $(1977,1980)$, Robles Báez (2014) e Iñigo Carrera (1997, 2007, 2013, 2013a). Más allá de sus diferencias, este grupo de autores señala la importancia de la forma mercancía como determinación de la conciencia del productor. Por otro lado, y en una suerte de vereda opuesta, existe otra tradición que se preocupa por la conciencia política y su naturaleza, pero poniéndola ahora como determinante y no determinada. Es decir, que considera a las relaciones de producción como determinando "la economía" o bien como una relación recíproca, introduciendo una dualidad entre la 
Siguiendo este punto de partida materialista, donde la conciencia está puesta como la forma consciente del ser social, esperamos mostrar cómo las transformaciones en la acumulación de capital, nacionales por su forma pero mundiales por contenido (Marx y Engels, 2012), determinan la expansión progresiva de la fuerza de trabajo calificada, el crecimiento de la importancia de la acción política del movimiento estudiantil y sus formas concretas a lo largo del siglo XX e inicios del XXI. Ubicados en el enfoque propuesto por la crítica de la economía política, buscamos no sólo describir la conciencia política del movimiento estudiantil -que es lo que comparte el conjunto de la bibliografía señalada-, sino explicarla como una mediación necesaria de la actividad humana enajenada en los productos privados del trabajo social en un momento histórico determinado por el desarrollo de las fuerzas productivas del trabajo social.

Expuesto nuestro punto de vista respecto de la conciencia, es necesario hacer una segunda observación metodológica respecto de la especificidad del espacio nacional donde tiene lugar la actividad del sujeto que es objeto de este trabajo. Esta exposición de la conciencia política que toma forma en los cambios del discurso de las direcciones reconocidas del movimiento estudiantil, tiene como determinación de

conciencia y su propia necesidad objetiva. Lo subjetivo determina lo objetivo tanto como lo subjetivo lo objetivo, sin nunca poder explicar la necesidad portada en su reciprocidad. Es decir, sin poder determinarlas como formas cualitativas de un único sujeto: la vida social. De esta forma reducen los descubrimientos de Marx a meras cuestiones de economía y explican la conciencia del productor tomando elementos de la tradición psicoanalítica naturalizando sus supuestos. Esta tradición se arraiga en Gramsci y tiene a Althusser como mejor expositor. A la vez que es el punto de partida para la llamada tradición posmarxista (Laclau y Mouffe, 1987; Zizek, 2003), respecto de la cual este trabajo busca hacer lo opuesto. Dicho esto último, cabe aclarar que, tomando en consideración el objetivo del artículo, nos posicionamos en la primera línea de los desarrollos expuestos.

\section{B}

ANUARI DEL CONFLICTE SOCIAL, 12 
su desarrollo la existencia de una renta diferencial de la tierra. ${ }^{5}$ Considerando que un tratamiento exhaustivo de esta última cuestión escapa a los límites del artículo, sintetizamos el modo en que la renta de la tierra minera determina la acumulación de capital nacional. ${ }^{6}$

Chile, al igual que otros países de la región, está determinado a lo largo de su historia como exportador de materias primas para el mercado mundial. Ya se trate de tipo minero, agrícola o ganadero. Esta determinación existe incluso antes de su vida como Estado nacional independiente (Salazar, 2003). Al producir dichas mercancías en condiciones naturales preferenciales, cuando la necesidad social solvente por las mismas crece, hace subir el precio comercial que rige el mercado mundial y ubica por debajo el precio de producción de las tierras o minas en funcionamiento. Esta diferencia permite que los capitales exportadores obtengan una ganancia extraordinaria que, por tener su origen en el pago de un "falso valor social" (Marx y Engels, 1973), llamamos renta diferencial de la tierra. En la medida que dicha masa de valor no va a reproducir al capital, si no a reproducir al terrateniente en tanto simple dueño de una condición de producción, su apropiación primaria puede verse interrumpida por otros sujetos sociales que buscan apropiarse de la misma por medio de mecanismos políticos (impuestos a la exportación, a la producción, tipos de cambio, etc.). Dentro de este conjunto de personificaciones que disputan la renta, además de sujetos nacionales, se encuentra el capital industrial extranjero que pierde parte de la plusvalía en la compra de dichas mercancías producidas en condiciones diferenciales. Este conjunto de determinaciones que han sido descritas de modo general, serán puestas fundamentalmente bajo la forma de la acción consciente del

${ }^{5}$ Ver infra, nota 7.

6 Para una aproximación preliminar y acotada de la estimación, ver Rivas y Kornblihtt (2017). 
movimiento estudiantil chileno que media, a través de su conciencia política, el ciclo económico determinado por la renta de la tierra. De este modo, más allá de su conciencia inmediata, el movimiento estudiantil objetivado en sus direcciones se afirma como parte de la organización autónoma, portada en los productos del trabajo social, de la división internacional del trabajo, es decir, del capital como el verdadero sujeto de la vida social. ${ }^{7}$

Aclarada la determinación mundial específica que tiene al movimiento estudiantil como expresión nacional de la lucha de clases, a partir de la revisión bibliográfica sobre lo escrito en torno al tema y sobre la base de avances propios en torno a la acumulación de capital en Chile, buscaremos reponer la unidad del movimiento propio de la vida social siguiendo las transformaciones de la conciencia política del movimiento estudiantil como portadora del desarrollo de las fuerzas productivas del trabajo social. En la constante búsqueda por aumentar la plusvalía relativa (Marx, 2009; Iñigo Carrera, 2013a) transforman, la división internacional del trabajo, de la cual Chile participa, fundamentalmente, como exportador de materias primas producidas en condiciones diferenciales, determinándolo como apropiador de renta diferencial de la tierra y dándole forma a los modos específicos de la acción política nacional. Dicho de modo sintético, ya aclarada estas determinaciones generales del espacio nacional chileno,

7 Sobre el capital como sujeto de la vida social existe una nutrida bibliografía. Dentro de las posiciones que identifican el carácter automático de la organización del modo de producción capitalista objetivado como dinero, pero sin llegar a ponerlo en unidad con la conciencia de los productores, encontramos los trabajos como los de Kurz (2016), Postone (2006) o Robles Báez (2014), entre otros. Entre aquellos que avanzan un paso más poniendo la forma de la conciencia de los productores como el modo de ser consciente del ser social, es decir, del capital como relación social, ver Tran Duc Thao (1971 y 2020) e Iñigo Carrera (2007, 2013a). 
esperamos mostrar a la conciencia política estudiantil como una forma determinada en la unidad de su movimiento histórico.

Nuestra crítica parte del período 1906-1930 que se abre con la fundación de la Federación de Estudiantes de la Universidad de Chile (FECH), y avanza por los ciclos de 1931-1981 y 1982-2011. Veremos cómo cada uno produce lo que podemos denominar provisoriamente un "lenguaje interior" (Thao, 2020) ${ }^{8}$ específico que determina el modo

8 Esto que llamamos "lenguaje interior" está portado en el sujeto como la determinación de su conciencia por medio de la cual se reconoce a sí mismo y resuelve idealmente toda contradicción real que media su reproducción como productor u órgano de la producción y el consumo social. Puesto en sí mismo como forma ideal general dominante en cada ciclo, se impone como el trasfondo social común generalizado que encuentra su necesidad en la organización práctica de la vida social. Dicho de otro modo, el "lenguaje interior" es la capacidad social interiorizada del sujeto para reconocerse como tal en relación a los demás. No existe lenguaje interior posible si no es como producto del conjunto de la vida social, por lo que todo individuo sólo puede referir a sí mismo como sujeto por medio de este telón de fondo a través del cual traduce para sí mismo el lenguaje de la vida real que emerge del proceso de intercambio y/o cooperación entre los seres humanos. En palabras de Tran Duc Thao, "el individuo no puede dirigirse a él mismo más que como ser social, como teniendo ya asimilada en sí mismo la forma de la reciprocidad social [...]. Es pues la materia social, como materia lingüística, la que por su forma recíproca depositada en las huellas cerebrales del individuo, produce este movimiento de idealización, donde la realización originariamente tendencial del significante y el significado se encuentra reenviada a ella misma, y deviene así la relación vívida del acto ideal de la conciencia y su significación intencional. «La conciencia es así, de entrada, un producto social». Este producto es muy particular porque, por una parte, se desprende del movimiento material que lo engendra - de modo que no puede ser considerado él mismo como material-; pero por otra parte, no puede separarse del movimiento material del que se desprende, porque existe precisamente sólo en el proceso de idealización, que parte constantemente de la forma recíproca del signo lingüístico mismo. En otros términos, el movimiento ideal del acto de conciencia se desprende del acto significante material como una figura, «se destaca» de su fondo, sin separarse de él, pues es la presencia misma de ese fondo la que le permite a la figura destacarse de él. El movimiento de la conciencia, producto de la materia lingüística, no existe pues, más que a partir de ella misma, o sea sigue perteneciendo a esa materia" (Thao, 2020: 45). Considerando lo dicho, lo que nos interesa es mostrar el 
consciente a través del cual es vivida la transformación de las formas económicas determinantes de la acción política de la dirección del movimiento estudiantil. El desarrollo expuesto termina visibilizando la emergencia de una nueva forma de conciencia que da lugar a nuevos partidos de izquierda de base estudiantil. En vista de esta transformación que llevó a la producción de partidos "estudiantiles" que hoy avanzan en su consolidación como partidos políticos de una fracción más amplia de la clase obrera chilena organizada-, esperamos contribuir a hacer consciente las determinaciones de la acción política pasada como modo de avanzar en la organización de una acción política que pueda dar cuenta de manera objetiva de su naturaleza presente. Es decir, ser organizada de modo consciente.

\section{El estudiante “clásico" y su conciencia anarquista. 1906-1930.}

Entre 1840 y 1871 en Chile predomina la industria artesanal. La introducción de la maquinaria en 1850 se impone hacia 1880 con una nueva expansión del mercado mundial. La industria manufacturera crece (Ortega, 1991) con el aumento de la renta de la tierra salitrera que fluye al espacio nacional (Meller, 1996; Reyes, 1994). ${ }^{9}$ Esta masa de valor extraordinario apropiado por los diferentes sujetos dentro del espacio nacional tracciona la acumulación del transporte, las comunicaciones, el comercio y otras actividades que demandan un aumento de la fuerza de trabajo calificada y no calificada (Cariola y Sunkel, 1982). La creciente demanda de brazos hace fluir a la

desarrollo inmanente sobre el cual toma forma la conciencia del movimiento estudiantil como el modo consciente de ser de una relación económica, siendo inseparable esta última de las formas ideológicas determinadas sobre las cuales los sujetos se reconocen como miembros de la vida social.

${ }^{9}$ Sobre la relevancia de la renta de la tierra en la acumulación de capital -que comprende la lucha política- en América del Sur, ver Caligaris (2014), Iñigo Carrera (2017). Sobre la renta de la tierra en general, ver Marx y Engels (1973). 
población obrera latente en el campo (Marx, 1973b, p. 517-606) a los diferentes centros urbanos. Mientras que en 1865 sólo el $29 \%$ de la población vivía en ciudades, para 1885 representaba el 42\%. Este número se mantiene relativamente estable hasta los años '30 (Lüders et al., 2016). La expansión del entramado industrial que crece alimentada por el flujo de renta de la tierra no sólo fortalece a los terratenientes. Las ingentes masas de dinero que afluyen al espacio nacional abonan el crecimiento de los capitalistas y la clase obrera ocupada en la industria manufacturera, quien también cobra relevancia en la gestión estatal y el trabajo intelectual que venía profesionalizándose sobre la base de fuerza de trabajo doblemente libre migrada de las provincias a la capital desde la segunda mitad del siglo XIX (Barría, 2015). Este fenómeno, que suele presentarse como una creciente importancia de los empleados públicos o "clases medias", va consolidando a la Universidad de Chile (UCH) como una porción de trabajo social independiente a cargo de producir a una parte de la fuerza de trabajo responsable de la gestión estatal.

Entre 1894 y 1923, la matrícula universitaria crece en promedio el $5,7 \%$ anual y pasa de tener 1.181 matriculados anuales en 1894 a 6.453 en 1930 (Lüders et al., 2016). Para 1906, los estudiantes de la Universidad de Chile, la mayoría futuros asalariados o productores independientes de mercancías (servicios) identificados con la clase obrera industrial y capitalistas antes que con los terratenientes agrarios, se afirman como sujetos privados y fundan la primera organización estudiantil independiente de América del Sur: la FECH (Moraga, 2012). Bajo principios "antioligárquicos", "liberales" y "anticlericales", media la colaboración del estudiantado con el movimiento obrero bajo la forma de asesoría jurídica, bolsas de trabajo, escuelas nocturnas (Garretón y Martínez, 1985) y una importante extensión cultural (Barrera, 1968). Como se puede apreciar, su principal forma de acción política no es inmediatamente la reivindicación gremial, sino la

B ANUARI DEL CONFLICTE SOCIAL, 12

DOI. 10.1344/ACS ACS 2021.12.12 
solidaridad con el movimiento obrero en expansión que lucha por regular las condiciones de compra y venta de su fuerza de trabajo.

Con el ideal de una transformación plena de la sociedad entendida como el "perfeccionamiento moral y cultural de los individuos" (Barrera, 1968: 619) los estudiantes participan en organizaciones como la Asamblea Obrera de Alimentación Nacional y las organizaciones obreras que aúnan a las crecientes organizaciones sindicales (Garretón y Martínez, 1985; Salazar, 2009). Su afirmación ideal es todavía más radical en la medida que más se consolida la industria y entra en aparente contradicción con los terratenientes agrarios por la apropiación de la renta salitrera. Las ideas liberales se radicalizan en la misma medida que prosperan los vínculos de dependencia indirectos bajo formas de sometimiento al capital industrial manufacturero. De la tradición radical arraigada en la Sociedad de la Igualdad de Bilbao, pasando por el radicalismo potenciado por el capital minero y el Partido Democrático formado por el artesanado, se desprenden los primeros grupos anarquistas y socialistas que se organizan en la efímera Unión Socialista (1887) (Grez, 2007). Este punto de inflexión evolutivo de la conciencia política de la clase obrera en desarrollo será el antecedente de un estudiantado radicalizado que se acerca cada vez más al pujante movimiento obrero.

El crecimiento del estudiantado como un actor político se afirma al tiempo que crece como proveedor de servicios o se convierte en asalariado. El futuro profesional se diferencia cada vez más del terrateniente y menos del obrero, pero también choca cada vez más con el capitalista. Al ver desaparecer su propia condición de vendedor de mercancías, se identifica con los padecimientos del ya existente obrero cualificado, proveniente de las relaciones de una incipiente manufactura. Este último sometido, al igual que el conjunto de la clase obrera, al desarrollo de la plusvalía relativa, va perdiendo el monopolio 
del proceso de trabajo y padece la especialización y la paulatina subordinación a la organización manufacturera del trabajo y la maquinaria que moviliza el capital industrial en expansión. Proceso de socialización de las capacidades de trabajo que atenta cada vez más contra la fuerza de trabajo semi-calificada que predominaba en la base artesanal precedente.

Producido como atributo del modo de producción capitalista, el estudiante se transforma junto con los cambios en la demanda de fuerza de trabajo. Como señalamos, el productor independiente de mercancías se proletariza. Esto habilita al estudiante a identificarse y establecer una unidad ideal con el resto de la clase obrera calificada que media su relación de solidaridad efectiva. Por un lado, se reconoce con el asalariado especializado en algún oficio y, junto con él, se indica su condición de productor independiente amenazado por las transformaciones de la división del trabajo que especializa los atributos de la fuerza de trabajo. Pero, además, considerando el modo específico bajo el cual el Estado ${ }^{10}$ en esos momentos impone las condiciones generales de reproducción al conjunto de la clase obrera, no es de extrañar que sean los ideales arraigados en la tradición liberal que luego van a decantar en expresiones ácratas los que conformen el lenguaje interior inicial del movimiento estudiantil (Grez, 2007). A través de este lenguaje interior traducirá como propio el interés de los demás obreros reconociéndose y diferenciándose como un sujeto específico .

Como mencionamos, durante principios del siglo $\mathrm{XX}$, el estudiantado contribuye activamente a la producción de los atributos políticos de la creciente clase obrera industrial. Estos atributos luego serán producidos directamente por el Estado. Sin embargo, para ese

${ }^{10}$ Sobre la especificidad capitalista del Estado, ver: Iñigo Carrera (2013) y Altvater (1976).

B ANUARI DEL CONFLICTE SOCIAL, 12

DOI. 10.1344/ACS ACS 2021.12.12 
momento, el proceso de instrucción y agitación política de los estudiantes es el modo de impulsar, progresivamente, el avance de la relación social general. La clase obrera industrial, consciente para sí misma gracias también a la acción del movimiento estudiantil, le impondrá a los capitalistas y terratenientes asociados en el Estado la nueva regulación de su propia producción por medio de tácticas violentas como respuesta a la acción política represiva de las demás clases (capitalistas y terratenientes) en el poder. Como partera de la organización jurídica estatal, la regulación general de la reproducción de la fuerza de trabajo sólo puede darse como un enfrentamiento directo de carácter político. Al no contar con formas jurídicas específicas instituidas, serán la huelga y la huelga política las principales herramientas de regulación del proceso general de compra y venta de fuerza de trabajo. Este proceso toma forma bajo el avance progresivo de su regulación legal desde 1901 con los primeros intentos del Partido Demócrata (Rojas, 2004).

En la medida en que el conjunto de la clase obrera crece numéricamente en el marco de la expansión industrial y se realizan las consiguientes transformaciones que impone la obtención de plusvalía relativa, más avanza la regulación y la reforma social (Narbona, 2015), al punto en que la clase obrera entrará a ser parte activa, políticamente representada, de su propia reproducción por el Estado. Hasta ese entonces, las condiciones generales de reproducción de la clase obrera se imponen "por fuera" del mismo. Visto como el modo normal bajo el cual las clases se imponen mutuamente sus condiciones de reproducción, no son sino la forma contradictoria, mediada por la lucha de clases, de imponer al Estado el proceso de expansión de las fuerzas productivas renovadas por la creciente transformación de la organización social del trabajo, personificadas por la clase capitalista y los obreros industriales en oposición a la clase terrateniente. Dicho de otro modo, el anarquismo y el socialismo, como formas determinadas 
del lenguaje interior de diferentes fracciones obreras, le imponen a los terratenientes las transformaciones de su propia relación social. En ambos, los dueños de la tierra verán su propia negación y desarrollarán sus propios modos ideales para mediar el conflicto social. El proceso de lucha que cubre todo el periodo parlamentario (1891-1924) parece inclinarse después de la primera guerra mundial hacia el lado de capitalistas y obreros. Estos se solidarizan frente al recrudecimiento de la lucha de clases por el control estatal como única forma de avanzar sobre la reducción de la masa de valor que apropia el espacio nacional a raíz de la crisis de la industria salitrera que pierde su condición natural diferencial y monopólica casi absoluta frente al salitre sintético. Se acelera, entonces, el proceso de disolución del viejo orden llamado "oligárquico", que refiere a los terratenientes como clase dominante en retroceso.

Tras la crisis iniciada con la primera guerra mundial que marca la acelerada contracción de la renta salitrera y posterior crisis política del régimen liderado por los terratenientes agrarios, los estudiantes se afirman cada vez más en oposición a estos últimos ("la oligarquía") por ser los responsables directos de la gestión estatal y del curso del proceso de acumulación. Su afirmación como productores libres, diferenciados cada vez más del régimen que cae para ajustarse a las nuevas condiciones creadas a lo largo del ciclo, toma la forma de una radicalización de sus posiciones liberales.

Para 1920, el movimiento estudiantil se identifica más con el anarquismo que con el liberalismo radical y desarrolla acciones de solidaridad con las organizaciones sindicales obreras, en especial con la International Workers of the World (IWW) radicada en Chile (Bastías, 2007; Garretón y Martínez, 1985) con gran presencia de obreros vinculados a trabajos artesanales, semicualificados o intelectuales (Sanhueza, 1997). Esta forma de conciencia es reforzada por el mismo proceso de reproducción de la clase obrera en su conjunto que toma la

\section{:}

ANUARI DEL CONFLICTE SOCIAL, 12

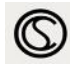

DOI. 10.1344/ACS ACS 2021.12.12 
forma de un enfrentamiento directo (y violento) con el Estado que, hasta 1925, opera como un garante en apariencia exterior de las condiciones generales de reproducción.

Con el fortalecimiento del capital industrial y la clase obrera, desde inicios del siglo XX el Estado incorpora una mayor reglamentación pero sin volverse todavía el agente a cargo de gestionar directamente la producción de mercancías bajo la forma de servicios garantizados, tal como luego entrarán en la reproducción de la clase obrera. A diferencia del ciclo posterior, el Estado se impone como un órgano inmediatamente ajeno a la propia reproducción de los obreros. El anarquismo, como lenguaje interior determinado del productor privado echado a su propia suerte, se afirma como tal en directa oposición al capitalista individual y al Estado visto como órgano ajeno que atenta contra su autodeterminación como productor. De ahí que, como forma específica que puede tomar el lenguaje interior de una porción de la clase obrera, encuentra un amplio lugar en el movimiento obrero más calificado y, como extensión de esta conciencia enfrentada al desarrollo de la manufactura, en el estudiante. $\mathrm{Y}$ es que, para este último, su formación como productor independiente, como una fuerza de trabajo que debe operar directamente sobre sí en el proceso formativo, sumado luego a los modos de su desempeño tanto como productor privado de mercancías u obrero especializado en una cadena administrativa, habilita una oposición radical frente a quien se levanta como la negación inmediata de dicha condición independiente: el Estado. Esto diferencia a la clase obrera más cualificada y al estudiantado como porción específica de la clase obrera respecto de la asalariada en la industria extractiva o manufacturera no calificada, quién, portadora de una fuerza de trabajo simple, se enfrenta inmediatamente a sí misma como parte de un 
proceso cooperativo de producción. Es decir, se reconoce inmediatamente como órgano indistinto del obrero colectivo ${ }^{11}$ y es más afín a los ideales del Partido Obrero Socialista (que nace en la industria salitrera) que al anarquismo y a la Federación Obrera de Chile $($ FOCH $)$ antes que a la IWW. ${ }^{12}$ Sin embargo, la conciencia anarquista que domina en el estudiantado irá mutando durante la segunda mitad de los años '20 con el golpe de la dictadura de Ibáñez. Como una de las tantas expresiones de este agotamiento evolutivo del anarquismo, la revista Claridad, órgano emblemático de la corriente anarquista dentro del movimiento estudiantil, desaparece en 1932.

La caída de la renta salitrera a partir de 1914 contrae el proceso de acumulación, debilita progresivamente al terrateniente agrario a cargo de la gestión estatal y abre una profunda crisis de representación política que recorre toda la década del '20. Esto habilita la alianza del capital nacional que se gesta durante el ciclo anterior junto a la clase obrera y la llamada "oficialidad joven". Por su reducida magnitud como fuerza independiente, el rol del estudiantado queda desdibujado frente a la dirección de los partidos obreros y el movimiento sindical. Pero el desarrollo de su "conciencia social", lenguaje interior por medio del cual se solidariza con el resto de la clase obrera y la expansión de la regulación estatal de la reproducción de la fuerza de trabajo, sienta la posibilidad de que esta misma porción calificada avance como gestora directa de las condiciones de reproducción de la clase obrera en su conjunto. Es así que, como bien señala Bastias (2007), muchos de estos ácratas migrarán a otras tendencias como son el Partido Radical, el Socialista, el Ibañismo o el corporativismo, y

${ }^{11}$ Sobre las transformaciones de la subjetividad productiva de la clase obrera y del capitalista de las cuales emerge el obrero colectivo, ver Marx (2009b).

12 Para una idea más detalles sobre la relación de los estudiantes con la IWW ver Sanhueza (1997) y Bastías (2007). 
hacen su entrada en la gestión de las diversas formas estatales que van tomando a su cargo la tarea de reproducir la vida de amplias porciones de la clase obrera. Ejemplo de ello son personajes como Eugenio Gonzales, futuro rector de la Universidad de Chile (UCH) y Oscar Schnake, fundador y primer secretario general del Partido Socialista (PS) en 1933 (Garretón y Martínez, 1985; Moraga, 2012).

El anarquismo, después de haber cumplido su rol, se hunde en la memoria histórica de la clase obrera para reflotar como un rejuvenecido lenguaje interior en los años ' 90 pero más marcadamente en los 2000, cuando, no por casualidad, el Estado parece volverse más ajeno a la sociedad al dejar servicios antes a su cargo en manos de capitales privados y tiene lugar una serie de enfrentamientos parciales que median la nueva política social después de la dictadura como son el llamado "movimiento de pobladores", la renovación de la "cuestión mapuche" y el mismo movimiento estudiantil. Enfrentado al Estado sin la mediación partidaria, los estudiantes encuentran en el anarquismo y demás ideologías "apartidistas" el modo de traducir en clave propia la nueva expansión de la clase obrera calificada en un contexto de mayor fragmentación y consiguiente cambio en las formas de gestionar el gasto social y la reproducción de la clase obrera. ${ }^{13}$

\section{El estudiante "nacional" y su conciencia popular y socialista. 1931-1981.}

La crisis de 1929 termina de liquidar el dominio político del terrateniente agrario sostenido en la propiedad de la tierra y la renta salitrera y da paso a una expansión del capital nacional en alianza con las diferentes fracciones de la clase obrera. Se abre un periodo que

13 Sobre la necesidad contenida en la existencia de la política social y la determinación de las formas de gestión estatal del gasto social se puede consultar Seiffer y Rivas (2017). 
genera la apariencia de estar frente al desarrollo del conjunto de potencialidades genéricas propias del modo de producción capitalista bajo la forma de un espacio nacional que puja por superar el "subdesarrollo" (Gunder Frank, 1968) o "la dependencia" (Marini, 1979; Sunkel y Paz, 1970). ${ }^{14}$ Esta apariencia, que parece surgir de fuerzas nacionales, es portadora de un proceso mundial (Marx y Engels, 2012 y 1968).

La ideología nacionalista, como una conciencia que reconoce al espacio nacional como uno portador inmediato del conjunto de potencias del capital en su determinación genérica, se consolida a lo largo del siglo XX y es la forma en que diversos procesos de acumulación se desprenden o recortan de los países "clásicos" (Iñigo Carrera, 2013) como procesos de acumulación independientes. Algunos dejan de ser colonias (Argelia, Congo) o bien avanzan en el desarrollo de sus potencias nacionales después de haberlas concentrado bajo la estatización del conjunto del capital en su interior (URSS, China, Vietnam o Cuba). Estos países parecen empezar a dar pasos para su afirmarse pleno en oposición al conjunto de fragmentos nacionales que dominan el mercado mundial. Se trata de un momento en que la clase obrera y parte del capital nacional empiezan a producir de manera generalizada una conciencia nacional específica que convive con la de aquellos sujetos que, en tanto "compatriotas", están aliados a los capitalistas de los países clásicos. La conciencia nacional, sea de izquierda o fascista, que prospera con el desarrollo del mercado interno fortalecido en el periodo de entreguerras se enfrenta a sus competidores inmediatos en el exterior como una conciencia antiimperialista y, hacia dentro, sobre respecto de la clase terrateniente,

14 Para una crítica en profundidad de las formas ideológicas de concebir la especificidad de América del Sur, se puede consultar Rivas y Casique (2020), Starosta y Steimberg (2019) e Iñigo Carrera (2013a). 
como "antioligárquica". En este momento de desarrollo del mercado mundial se generaliza en un conjunto de países una conciencia que se afirma inmediatamente como "nacionalista". Se trata del modo ideal típico a partir del cual los estudiantes chilenos desarrollarán una nueva forma de lenguaje interior para referir a su acción política en el nuevo ciclo.

Esta conciencia nacional se expande al punto de ser una forma de solidarizarse internacionalmente como "naciones oprimidas", de "tercer mundo" o, en sus versiones más locales, "latinoamericanistas". Dicho de otra manera, el antiimperialismo, presente durante todo el periodo "nacional y popular", se generaliza como forma por la cual, en el propio espacio nacional, la clase obrera y los capitalistas locales son mediaciones en el enfrentamiento de los países que, en oposición a las viejas naciones europeas dominantes y a los EE.UU., pujan por afirmarse como competidores en el mercado mundial. Nacionalismo y antiimperialismo son dos modos de la misma afirmación históricamente determinada. La diferenciación nacional, como un afirmarse de cada nación, es la forma de la conciencia política universal del modo de producción capitalista (Dachevsky, 2021). El nacionalismo es el modo invertido de realizar la unidad general de un vínculo social mundial, cuyo principal medio de afirmación es la relación igualada entre los productos del trabajo privado por medio de la formación de la tasa general de ganancia (Marx, 2009a; Iñigo Carrera, 1997). El mismo se presenta sin embargo invertido como la diferenciación de las personas agrupadas por la sangre o el suelo.

En los países cuya especificidad pasa por la producción de materias primas para el mercado mundial, como es el caso de Chile, la conciencia nacional se refuerza con la expansión de la industria liviana (Lagos, 1966; Ortega, 2005) y la transformación de los modos en que el Estado apropia la renta de la tierra. Se realiza bajo la apariencia de ser una masa de valor producida en el propio espacio nacional, al 
punto de habilitar la disputa por la propiedad directa, ya no sólo de la tierra, sino del mismo capital extranjero que opera en el territorio. Demasiado débil cada sujeto por sí mismo como para apropiar dicha riqueza, su acción sólo puede tener lugar como un proceso solidario. La unidad de acción no puede estar puesta en otro lugar que no sea en el representante político del capital social total: el Estado, quien aparecerá en todo este periodo como el sujeto del proceso de acumulación. El principal campo de disputa será su administración directa. Como consecuencia, las viejas ideas se marchitan y el anarquismo -con un sentido mucho más cosmopolita- no tiene lugar. Este proceso, reflejado en la conciencia de la clase obrera, emergerá como una pujante lucha de liberación nacional por el control estatal frente al terrateniente y al capital extranjero primero y contra los mismos capitalistas nacionales después. Como veremos, los estudiantes no serán ajenos a este proceso, sino que reflejarán en su conciencia bajo formas ideológicas específicas este nuevo lenguaje interior producido por las transformaciones de la división internacional del trabajo cruzada por la primera y segunda guerra mundial.

Como ya se dijo, Esta nueva forma de conciencia se refuerza, por un lado, con la expansión de la industria manufacturera que pasa de ser el 10\% del producto en 1930 al 20\% en 1950 y el 25\% en 1973 (Lüders et al., 2016) aparentando un proceso de desarrollo similar al de los países "clásicos". Por otro, por la continua expansión urbana que abarca al 53\% de la población en 1940 y al 75\% en 1970. Pero, sobre todo, se verá reforzada por el nuevo rol del Estado en el proceso de reproducción de la acumulación que surge de la lucha solidaria de capitalistas nacionales y diversas fracciones de la clase obrera urbana en desmedro de los terratenientes y la clase obrera rural (Reyes, 2015).

Como ya mencionamos, a diferencia del ciclo anterior, el Estado produce directamente las condiciones de reproducción de la 
clase obrera mediado por la lucha partidaria entre diferentes clases y fracciones de clase, organizadas de modo independiente bajo la forma de partidos. La clase obrera encuentra lugar en el Estado y participa de su gestión porque la burguesía, en primera instancia, no puede sino buscar, al igual que el terrateniente, su interés privado. La representación política de la clase obrera y su consolidación dentro del Estado como el antagonista que le impone en la competencia las condiciones generales de producción a los capitalistas, es una necesidad impulsada por la reproducción normal de la acumulación. El representante político del fragmentación nacional del capital social, frente a la creciente demanda de fuerza de trabajo con atributos más o menos universales demandados por la manufactura, expande su producción abaratada bajo la forma de crecientes derechos sociales (en salud, educación y organización sindical) que se imponen mediados por la lucha de clases. La universidad, como espacio de producción de mano de obra calificada, también crece y reproduce esas mismas contradicciones. Ahora no sólo se forma el hijo de "la clase dominante" o la "élite".

Para 1931, la UCH da un paso en su afirmación como productora privada bajo la forma de un proceso de reforma que la pone, si bien aún como una porción de la propiedad pública, ${ }^{15}$ como una con igual independencia administrativa formal frente a otros productores privados (como la Universidad Católica) al lograr su autonomía jurídica. Esa liberación de la UCH de la dirección estatal directa será la forma más potente para poner en producción nueva fuerza de trabajo calificada. Entre 1935 y 1948 la UCH crea ocho facultades nuevas (Barrera, 1968). La educación superior, traccionada

15 Desde el punto de vista de la unidad del proceso de reproducción social que tiene como forma simple la producción privada, la propiedad pública no es otra cosa que la propiedad privada del Estado. 
por el capital industrial en expansión, ve ampliada su capacidad de incorporar nueva fuerza de trabajo a una tasa del 4,9\% anual entre 1935 y 1952. Mediado por el ciclo expansivo que inicia la entrada del capital medio fragmentado a fines de los '50 en toda la región sudamericana (Iñigo Carrera, 2013a) y que impulsa la reforma universitaria de fines de los '60, crecerá al 16\% anual entre 1961 y 1972 (Lüders et al., 2016). En ambos procesos, los estudiantes jugarán un rol importante, pero, de igual manera que en el ciclo anterior, sin sobrepasar el protagonismo de las organizaciones sindicales y partidos obreros. Es más, se desarrollará subordinada a los mismos.

El movimiento estudiantil aparece en sus direcciones estudiantiles como portador del aparente pujante desarrollo nacional. $\mathrm{El}$ anarquismo, como una conciencia que se reconoce primero en el productor independiente antes que en la nación -ambas formas ideológicas- da paso a una conciencia bajo la cual el estudiante universitario, diferenciado del obrero industrial y sin dejar de percibirse como un productor independiente -dueño de su trabajo-, se concibe derechamente como un "pequeño burgués" (Garretón y Martínez, 1985). Lo que antes destacaba el anarquismo y contraponía como figura específica se presenta como la imagen negativa del estudiante que se afirma como un sujeto nacional y popular. Durante los años '30, el movimiento estudiantil leerá su pasado reciente como expresión ideal de dicha condición de propietario y se rechazará a sí mismo a modo de identificación con el resto de la clase obrera. A excepción de algunos gremios caracterizados por estar conformados por fuerza de trabajo semi calificada, el anarquismo quedará como negación de la nueva conciencia estudiantil. ${ }^{16}$ En cambio, ganarán

16 Toda determinación es negación y toda negación afirma, como lo otro de sí mismo, lo que no es ella. Como veremos más adelante, el "ser pequeño burgués" funciona, en este nuevo lenguaje interior de los estudiantes, como el modo concreto 
lugar las ideologías de corte partidario y nacionalista, que van desde el nacionalismo corporativista de la Falange Nacional -fundada en 1935 y antecedente de la Democracia Cristiana (DC)-, la necesidad de la "revolución burguesa" del Partido Comunista (PC), el indoamericanismo presente en el PS, y pasan incluso por el nacional socialismo encarnado por el Movimiento Nacional Socialista de Chile. A diferencia del ciclo anterior y más allá de sus variaciones, la conciencia estudiantil será predominantemente nacionalista. Modos diversos de reafirmar la soberanía nacional o considerar al espacio nacional como soberano, más o menos oprimido por una fuerza exterior determinada como "imperialista".

Horrorizado por su condición de "pequeño burgués", el movimiento estudiantil se verá a sí mismo como una fuerza subordinada al movimiento obrero sindical y sus partidos. Primero como grupos universitarios, pero rápidamente, durante los años '30, en la conformación de juventudes políticas. ${ }^{17}$ A su vez, en sintonía con la situación mundial, partidos y juventudes reproducen los enfrentamientos de tales o cuales "naciones dominantes". En los años '30, será muy común que la juventud se enrole en la lucha fascista y antifascista, y reproduzca sus alianzas y modos de enfrentamiento. Para fines de la misma década, la FECH, afirma su giro ideológico nacional de izquierda, dirigida por el Grupo Universitario Antifascista (GUA) y a fines de la década proclamará la candidatura de Pedro

en que estos niegan inmediatamente su carácter de obreros cualificados y, en esa negación, afirman a la clase obrera manufacturera como el sujeto de cambio, mediando así su subordinación al movimiento obrero organizado políticamente a nivel sindical. Lo que no excluye, sino que complementa, la existencia de organizaciones y partidos más representativos de estos sectores de la clase obrera asalariada que, de una u otra forma, se ven como diferentes del movimiento obrero "industrial" y se agrupan como "empleados".

${ }^{17}$ Mientras que el PC armó las Juventudes Comunistas en 1932, el PS fundó sus propias juventudes en 1935. Ver Garretón y Martínez (1985) y Moraga (2012). 
Aguirre Cerda (PR-PS-PC). Entre 1938 y 1945, el movimiento estudiantil, por primera vez, no aparece como opositor al gobierno de turno (Garretón y Martínez, 1985). Esta relación queda rota durante el gobierno de Gonzales Videla quien, en nombre del mismo espíritu nacional, ilegaliza al PC. Hasta la derogación de la llamada "ley maldita", los estudiantes serán oposición al gobierno. Al interior del movimiento estudiantil, la conciencia nacional choca con la presencia de un partido obrero que aparece, a la conciencia de otros obreros organizados de modo independiente, como la negación de la autonomía nacional. Se extiende la conciencia anticomunista y tienen lugar los enfrentamientos entre comunistas y socialistas. En 1940 existían dos federaciones estudiantiles, una dirigida por el comunista Jorge Lillo y otra dirigida por Aguirre Tupper (Garretón y Martínez, 1985). Esto habilita, entre otras cosas, a que los sectores conservadores se muestren con una conciencia independiente de ambos polos y afirmándose como inmediatamente estudiantil de modo "apartidista". En 1946, por primera vez, la derecha gana la conducción de la FECH y nace "el gremialismo universitario" como fuerza política. Todo sin dejar el espectro nacionalista.

A pesar de lo anterior, el movimiento estudiantil se vuelve a afirmar en los años '50 como subordinado al movimiento obrero, determinado por su reducido número en relación al resto de la clase obrera y su fuerte diferenciación en atributos, junto a su proletarización parcial. Vendedores de servicios, en muchos casos, su identificación ideal sólo puede afirmarse negándose como parte de la clase obrera identificada en el mundo que impone la manufactura. Su diferenciación, en tanto obreros calificados o productores de mercancías en vías de proletarización, se niega en su propia percepción como algo diferente del resto del proletariado no calificado. Al reconocer su rol como vendedor de mercancías, en oposición a la clase obrera industrial, el "pequeño burgués" -dueño de su producto- se 
contrapone al obrero. Pero es esa misma diferencia la que llama a la solidaridad. En oposición a su propia autopercepción -que le brota de ser un productor privado calificado-, la condición de reproducción proletarizada le impone una unidad con la clase obrera asalariada más allá de su conciencia espontánea. Debe negar su apariencia tomando como necesidad un puro mandato moral afirmado ya no en su condición inmediata de productor, sino en la unidad nacional que precede su diferencia. Ve en el obrero industrial, y no en él mismo por no reconocerse como obrero- la potencial liberación nacional, ergo, la propia liberación como parte de la nación. Esta autopercepción, como la traducción social generalizada del sentido de las experiencias vividas, sumado al rol de los partidos en el proceso de reproducción de la vida obrera, no da lugar al desarrollo de una conciencia política que se reconozca inmediatamente como gremial, como sí ocurrirá en el ciclo posterior. El "gremialismo", como la afirmación política en tanto simple estudiante, es minoritario, por lo que aparece como el mejor medio para la afirmación de los sectores aliados con la clase dominante, vinculado, principalmente, con la derecha y la conservación de lo existente. De ahí que sea la juventud militante de partidos políticos el principal medio de organización de la conciencia política del movimiento estudiantil durante este periodo. Mientras que en la IWW convivían los estudiantes con otros órganos privados de la clase obrera, el partido supone una acción más centralizada como un único órgano privado. Si uno se trata de un vínculo solidario organizado como coordinación más o menos centralizada de organismos formalmente independientes, ${ }^{18}$ el otro supone una organización centralizada desde un comienzo, sin dar cabida a la independencia formal al interior. Esto no excluye la disputa de quienes

18 Diferencia expresada, por ejemplo, en el debate entre federalistas y centralistas en la IWW. Ver Bastías (2007).

\section{B}

ANUARI DEL CONFLICTE SOCIAL, 12

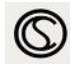

DOI. 10.1344/ACS ACS 2021.12.12 
lo componen como órganos independientes, como individuos libres preexistentes, sino que determina la forma específica del conflicto. La centralización partidaria refleja, por otro lado, la forma de organización estatal igual de centralizada. Esto pone a los partidos como los principales, aunque no exclusivos, productores del personal político para la gestión estatal. Serán ahora los partidos "marxistas" o "socialistas", inspirados en los triunfos de partidos obreros en otros países, el medio por el cual se trascenderá la autopercepción "pequeño burguesa" del estudiante. Esto les permitirá establecer el vínculo solidario con la clase obrera a través del "ideal nacional" específicamente antiimperialista y antioligárquico como el modo social incorporado para indicarse a sí mismo como ciudadano su ser social nacional y la naturaleza de su acción. Si bien el gremialismo como una conciencia política específica no deja de ser una forma de la conciencia política de los estudiantes, se puede mantener "reprimida" o reducida como patrimonio de los antagonistas directos de la clase obrera en expansión y organizada. De este modo, presidido por las juventudes políticas y en alianza con la recién fundada Central Unitaria de Trabajadores (CUT), ${ }^{19}$ el movimiento estudiantil encara el proceso inflacionario derivado de la creciente presión que ejercen el conjunto de capitales -nacionales y extranjeros- sobre la renta diferencial minera que crece con el alza de precios del cobre desde fines de la guerra hasta 1955. La caída en 1957 desata una huelga general política de masas -gatillada por el alza de precio del transporte- donde los estudiantes luchan codo a codo con la población obrera industrial, pero, sobre todo, con la población obrera sobrante (Marx, 2009) que, para esos años, produce formas de acción políticas independientes como "movimiento de pobladores" (Milos, 2007; Salazar, 2006).

${ }^{19}$ La Central Unitaria de Trabajadores se fundó el 12 de febrero de 1953.

\section{B}

ANUARI DEL CONFLICTE SOCIAL, 12

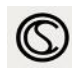

DOI. 10.1344/ACS ACS 2021.12.12 
A finales de la década del ' 50 , se produce un nuevo salto en la expansión de las fuerzas productivas del trabajo social que impulsa la entrada del capital medio fragmentado al espacio nacional como nueva modalidad en la apropiación de renta (Iñigo Carrera, 2013:144-178). El proceso tiene en su base además la progresiva expansión de la población obrera excedentaria para el capital que fluye del campo, se agolpa en las ciudades y debe luchar por igualar sus condiciones de reproducción con el resto de la clase obrera (Garcés, 2002). Sin representación política plena, desarrolla sus modos de acción independiente. Eso crece en el marco de la radicalización de los enfrentamientos entre el capital nacional, el extranjero y la clase obrera, empujados por el nuevo aumento de la renta diferencial minera desde 1964 que coincide con la caída progresiva de la rentabilidad del capital a nivel mundial (Duménil y Lévy, 2002; Iñigo Carrera, 2013a). La población obrera sobrante, necesitada de un personal político más o menos independiente, atrae progresivamente a importantes porciones de estudiantes a la izquierda de los partidos reformistas más apegados a la "clase obrera industrial". La primera organización que ve en ese sector una potencia transformadora será el Movimiento de Izquierda Revolucionario (MIR) que, en 1969, da un giro "guevarista" y desprende a las fracciones políticas más ligadas a la clase obrera organizada sindicalmente (Neghme y Leiva, 2000; Valenzuela, 2008). El año anterior, el movimiento estudiantil venía impulsando la reforma universitaria como modo de expandir y modernizar la universidad en vistas del crecimiento correlativo de la población obrera y la demanda del capital industrial. Cada vez más necesitada de calificarse para vender su fuerza de trabajo, choca con la especificidad de la acumulación nacional.

El proceso de fragmentación de la clase obrera emerge como una diversidad de formas de acción política, muchas de ellas contradictorias entre sí. Una serie de procesos de fraccionamiento 
interno de los partidos de izquierda tradicional y de centro (como la Democracia Cristiana) se torna expresivo de la situación. La juventud estudiantil, en consonancia con las formas de organización de luchas directas de la clase obrera, radicaliza su propia conciencia nacional y avanza en la organización de la fuerza política de dicha fracción del proletariado. Al entender la necesaria alianza con el resto de las fuerzas obreras y fuertemente inspirada por el proceso cubano, las críticas al estalinismo y al avance de la Democracia Cristiana, se presenta como la lucha directa por el socialismo, es decir, por la soberanía plena de la clase obrera sobre el conjunto de la propiedad que conforma dicho recorte nacional. Nace así "la izquierda revolucionaria" o "nueva izquierda" 20 que busca dar paso a "la patria socialista" y encuentra su necesidad en los desarrollos de la teoría marxista de la dependencia (TMD) y la teología de la liberación ${ }^{21}$, teniendo a la experiencia cubana como "modelo". Este sector de la clase obrera profesional, al alero del rechazo de su supuesta condición "pequeño burguesa" -algo muy bien expresado en el ensalzamiento idealista que hace el guevarismo del "hombre nuevo", por ejemplo-, no sólo impulsa los procesos de modernización universitaria a fines de los ' 60 , sino que comienza a liderar el proceso de disputa por la renta minera impulsado de manera más radical por la población obrera sobrante. Ya no es sólo el "proletariado industrial", serán también los "pobres del campo y la ciudad” que saltan al combate abierto desde 1957.

En este escenario, la clase obrera de los años '70 parece personificar la potencia genérica de avanzar sobre los límites de la

${ }^{20}$ Si bien el MIR es fundado en 1965, en 1969 da el giro ideológico que lo separa del sindicalismo tradicional y determina su acción durante los años '70. Ese mismo año aparece el Movimiento de Acción Popular Unitaria y en 1971 se funda la Izquierda Cristiana. Todos partidos de fuerte composición juvenil.

21 Sobre el impacto de estás corrientes ideológicas en los sectores políticos que conforman la izquierda extraparlamentaria está el trabajo de Lozoya (2020).

\section{$\stackrel{\mathrm{B}}{\mathrm{B}}$}

ANUARI DEL CONFLICTE SOCIAL, 12 
propiedad circunscrita a su recorte nacional. Sin embargo, su propia forma democrática se vuelve contra ella cuando se pone en juego la centralización de la fuerza. En el gobierno, pero sin ser mayoría en el parlamento y en la justicia, ni controlar al conjunto de fuerzas armadas (anticomunistas), los partidos políticos de la clase obrera -y con ellos sus juventudes y el movimiento estudiantil- no terminan de producir un vínculo solidario que pueda superar la forma de organización democrático burguesa del Estado. Producto de la fragmentación que tiene en su base la proliferación de pequeños capitales que florecen gracias a los diferentes modos de apropiarse renta de la tierra, la clase obrera produce disímiles formas de conciencia que encuentran su punto de convergencia en su interés inmediato y se apoyan en la democracia como el modo -en apariencia- más potente para su realización. Al mismo tiempo, como condición del régimen, se enfrenta de manera contradictoria con su propio impulso a la estatización. La conciencia democrática, como la forma de conciencia nacional de la clase obrera, se vuelve, en el periodo de crisis, la negación de su potencial acción centralizada. Esta acción, impuesta por la propia crisis del proceso de acumulación, quedará en manos de la fracción obrera que personifica directamente al espacio nacional bajo la coerción directa como modo de garantizar la unidad del conjunto de la producción privada: los militares. Aliados con terratenientes, capitalistas nacionales y extranjeros, diezman a la clase obrera y a la vanguardia estudiantil imponiendo la necesidad de continuar la acumulación de capital, destrabando la lucha de clases que tiene en 1973 su punto más álgido.

Como vimos en este apartado, para fines de los ' 60 , a diferencia de las disputas entre comunistas y socialistas de los años '30, la fragmentación queda mediada por las crecientes discrepancias entre "la nueva" y "la vieja" clase obrera y marca la vida del movimiento estudiantil. Este reproduce sus contradicciones bajo la forma de un 
lenguaje interior donde afirma su acción como "pequeño burgués", negándose como una porción de la clase obrera y afirmando su solidaridad con el rodeo de la nación oprimida. Sin embargo, a pesar de "la originalidad", en ningún momento el movimiento estudiantil deja de estar subordinado a la clase obrera, sus partidos y organizaciones sindicales. Se encuentra unido subordinadamente por sus propias representaciones ideológicas, sin superar nunca el carácter nacional de su conciencia.

\section{E1 estudiante “fragmentado" y su conciencia democrática radical. 1982-2011.}

La progresiva contracción de la renta minera respecto de la necesidad del espacio nacional para reproducirse de manera ampliada se resuelve como una enorme crisis política que reorganiza no sólo las alianzas de los partidos. En 1980 una vez más se reforma la carta constitucional. Esta formalización del proceso de apertura en curso, sentará las bases para que -de modo ahora regulado- el Estado avance en nuevas formas de expandir el proceso de acumulación, mientras Chile pierde lugar en la competencia mundial a raíz de la ampliación de la brecha productiva con el capital medio (Rivas y Kornblihtt, 2017). Como ya se dijo, la unidad del proceso de reproducción pone a los militares -que ven en "el marxismo" y en la clase obrera industrial una amenaza a su propia reproducción- en unidad con el terrateniente, el capital nacional y el extranjero. El aliado de antaño de la joven oficialidad, ahora es una amenaza. Sin abandonar inmediatamente su forma nacionalista, los militares se afirman en su anticomunismo. En Santa Alianza, el conjunto de clases propietarias descarga su furia contra la clase obrera, tal como había sucedido cuando el PC fue ilegalizado. Pero, la magnitud de la clase obrera que creció debido a la migración del campo a la ciudad y las proliferantes organizaciones que sobrepasan a los viejos PS y PC, empujan al Estado a la organización sistemática de 
su liquidación. Esto que se replica en otros países de América del Sur, en la medida que hace a una determinación compartida por otros países, habilita una organización de la represión de la clase obrera y sus partidos a escala internacional (Plan Cóndor de 1975).

Frente a la necesidad de sostener el proceso de acumulación, con el endeudamiento como el principal medio disponible (FfrenchDavis, 2018) y limitados por la acción norteamericana, los militares aperturistas se imponen a los nacional desarrollistas con la fuerza de sus aliados "librecambistas" (Gárate, 2012). La caída de la renta diferencial minera, que pone a la deuda como el modo inmediato más potente de sostener la reproducción del capital social total, empodera a "neoliberales" sobre "desarrollistas". Ahora bien, no es que porque cambió la determinación ideológica cambie la reproducción material. Es el desarrollo propio de la especificidad material que se afirma como unidad mundial que demanda una transformación ideológica determinada. El giro ideológico es, finalmente, práctico. La forma concreta de esta necesidad práctica que impone como condición de endeudamiento se levanta sobre los materiales ideológicos dejados por la generación anterior pero que no encontraban lugar. Ahora, como modo del desarrollo consciente pueden alzar vuelo como formas ideológicas dominantes, determinantes de un cambio en los modos del lenguaje interior de los productores.

La reforma universitaria de 1967, que abre a la Universidad Católica al intercambio con la Universidad de Chicago, brinda el nuevo personal político civil (Silva, 2012). Éste, en alianza con la dictadura, gestionará el pujante proceso de apertura que demanda la reproducción de los capitales individuales. Los militares se convierten ahora en neoliberales, aliados al capital extranjero y al capital nacional que ve amenazada su existencia por la fuerza mostrada por la clase obrera en búsqueda del "socialismo". Pero, además, las ideas neoliberales, como promotoras acérrimas de los vínculos mercantiles, 
son también la forma más potente para desprender del Estado una serie de funciones que demandan una escala que él mismo no puede realizar. La dictadura no sólo libera el mercado, sino también a ciertos capitales de un conjunto de relaciones con el Estado de las cuales dependían para reproducirse. La venta de empresas públicas termina de consolidar el sacrificio y reorganización de parte de la burguesía nacional, dando paso a nuevos capitalistas que madurarán como "nuevos grupos económicos" (Undurraga, 2011) sobre los influjos del capital financiero que emerge después de la crisis de mediados de los '70. Luego, la apertura de mercados no transables antes monopolizados por el Estado es el reverso necesario del proceso de destrucción de otras ramas como la textil o la metalmecánica (Gatica, 1989). El capital da, pero también quita. Bajo la forma del Estado gestionado por el mando militar, el capital busca asegurar su reproducción en contra de la clase obrera. Donde lo que prima es el interés privado como forma de realizar el interés general del capital como relación social, la organización estatal opera guiada por su propia necesidad enfrentada al conjunto de intereses particulares (tanto de capitalistas como de obreros) e imponiendo a las clases sociales sus condiciones de reproducción por medio de la lucha política legal o ilegal. Ahora, bajo la apariencia de liberar parte demoguila producción directa de determinados atributos de la clase obrera -sin retirarse del todo-, gestiona la reproducción de esta última bajo la forma de una creciente participación del capital individual, acelerando el proceso de su fragmentación.

El nuevo impulso en el desarrollo de las fuerzas productivas, avanza modernizando las formas de organización industrial en los ' 80 y ' 90 , liquida el capital mercado internista y renueva las inversiones de capital, sobre todo en las ramas exportadoras, el transporte y las comunicaciones (Moguillansky, 1999). Además de los precios altos del cobre -que suben desde 1984 hasta mediados de los '90- fluye la

B ANUARI DEL CONFLICTE SOCIAL, 12

DOI. 10.1344/ACS ACS 2021.12.12 
inversión extranjera. Se transforman las organizaciones de las empresas y crece la demanda por fuerza de trabajo calificada (Lüders et al., 2016). Una primera etapa de esta expansión de la producción de obreros y obreras calificadas encuentra su base en la población sobrante expulsada del campo primero, por los giros de la reforma agraria (Kay, 1998) y de la producción industrial durante la crisis del '82, después (Gatica, 1989). Población que, en gran medida, migra a Santiago (Lüders et al., 2016). Es decir, la clase obrera vista en su conjunto ve potenciada su capacidad de extender sus atributos en base a su propia diferenciación. La fragmentación brota, por lo demás, como producto de la consumación del sueño "desarrollista" de la reforma agraria, la posterior modernización del agro y la casi total urbanización de la población (Lüders et al., 2016). La realización del sueño de liquidar al terrateniente como sujeto político, es la forma de, por otro lado, agotar la fuente de población obrera latente. Esto tiene una primera expresión en la apertura migratoria que atrae a la población obrera peruana expulsada de su espacio nacional durante la crisis de fines de los '80 y que arriba en masa a Chile desde 1992 (Canales 2018). Gran parte de esta masa de fuerza de trabajo libre se agolpa como sobrante en las ciudades y se vuelve base para la expansión de la demanda de obreros calificados ocupados principalmente en el servicio doméstico y de cuidados (Stefoni, 2005).

Después del ciclo expansivo que brota de la irresuelta crisis de sobreproducción de mediados de los '70, con base en el endeudamiento externo y una creciente sobrevaluación del peso, la llamada "crisis de la deuda" expulsa a estos capitales, liquidados como propiedad del capital financiero. Sobre esto, la salida de ingentes masas de obreros se suma a otras capas estancadas como sobrantes -venidas de la modernización agrícola- en los diferentes centros urbanos. Para la crisis de 1982, el $82 \%$ de la población vive en ciudades y el desempleo alcanza el 25\%. La crisis económica gatilla el inicio de una 
crisis política. Aumentan las movilizaciones obreras que sentarán las bases para la expansión de la lucha democrática que se vuelve viable con la expansión del proceso de acumulación desde 1984. El proceso de transformación económica que irá habilitando la incorporación progresiva de la infantería femenina (Abramo, 2004), ampliará el salario de algunos sectores y permitirá expandir la capacidad de consumo de la familia obrera (Jadresic, 1990). Lo que comprende el acceso a la educación superior (Lüders et al., 2016). Esta liberación de fuerza de trabajo femenina tendrá por condición la delegación de los trabajos de cuidados que tenía a cargo como expresión de su vínculo de dependencia personal, a través del cual podía acceder al salario obrero, cubierto ahora por el proceso migratorio, sobre todo por el acaecido en los ' 90 . El crecimiento de la población obrera calificada en una primera etapa es inseparable de este abaratamiento en los costos de reproducción familiar de esta porción de la población que queda a cargo, por medio de vínculos económicos, del trabajo doméstico. Esto explica también que la expansión de la producción del obrero calificado crezca primero en los grupos de más ingresos para luego crecer en los demás (Orellana, 2011). En la medida que se puede ampliar la ocupación de las mujeres de la población obrera, es posible ampliar el salario obrero y más partes de la clase obrera sobrante ocupan los puestos que abre la industria del trabajo doméstico.

Ahora bien, en este nuevo ciclo, la reproducción de la clase obrera se resuelve mediante su diferenciación. Por un lado, queda el Estado bajo la forma de "políticas focalizadas", por otro, está a cargo del capital privado. Atado este último al primero -que hace de condición de su reproducción-, se desarrollan formas específicas de subsidios. Lo que antes se obtenía por medio de la financiación de la oferta, ahora aparece como subsidio a la demanda. Se trata de un cambio de forma, más no de contenido. Chile, a pesar de los cambios formales, sigue desarrollándose como órgano específico del mercado 
mundial. Su condición de productor de materias primas no cambia, más bien se consolida en oposición del aparente desarrollo industrial nacional, apareciendo para algunos como un proceso de desindustrialización (Ahumada, 2019; Gatica, 1989). El capital mercado internista derrotado en la competencia da curso a los capitales comerciales importadores y refuerza el cambio de las viejas formas de reproducción de la clase obrera. Muy pequeño como para ser un mercado que amerite una producción directa como forma de apropiación de renta, se presta para el crecimiento del capital comercial. Dentro del conjunto de mercancías que trae, importa las nuevas formas culturales bajo las que las nuevas generaciones desarrollan un lenguaje interior nuevo por medio del cual se diferenciarán de la anterior.

La proliferación de los vínculos mercantiles no estatales mediados por la acción del Estado empuja a la consolidación del carácter privado de la UCH como una organización independiente. El decreto ley de 1981 (Moraga, 2006), que termina con el oligopolio de las viejas universidades tradicionales (la U Católica y de Concepción son privadas), las empuja a formar un cártel: el Consejo de Rectores de las Universidades Chilenas (CRUCH) cuya unidad pasa por la obtención de los Aportes Fiscales Directos (AFI). ${ }^{22} \mathrm{Si}$ bien la UCH es desmembrada y puesta a competir consigo misma, con las preexistentes y nuevas universidades privadas, en su conjunto están sujetas a formas de financiamiento específicas. Por lo que, frente a sus nuevos rivales, son aliadas. El decreto ley de 1981 consuma el proceso que ya en 1931 le entrega autonomía a la UCH desarmándola y liberándola a la competencia como productora independiente pero financiada directamente por el Estado. Nuevamente, es el Estado el

${ }^{22}$ Ver infra, nota 19.

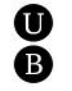

ANUARI DEL CONFLICTE SOCIAL, 12

DOI. 10.1344/ACS ACS 2021.12.12 
medio por el cual se impone la nueva forma de los vínculos indirectos y toma la apariencia de un acto político deliberado que no obedece más que a las "ideas dominantes". Sin embargo, como es propio del modo de producción capitalista, la necesidad de expandir la producción de una mercancía específica no excluye que se presente como la negación de su carácter mercantil. Si no que aparece antecedido por un proceso que, en apariencia, recuerda al de la acumulación originaria, como afirman aquellas visiones que asumen la acumulación nacional como un producto de una permanente desposesión (Kremerman, 2016). El decreto, en una primera instancia, no autonomiza a la universidad, sino que permite la imposición de un proceso de ajuste dirigido directamente por los militares. Se trata de un proceso que la fuerza a volverse autónoma, pero sin que termine de existir una fuente de financiamiento específica que la mantiene compitiendo en vínculo directo con el Estado. Luego, durante el proceso de expansión de la economía, su autonomización forzada y tutelada por el Estado da curso a su afirmación como fragmentos independientes. Pero esto sólo puede tener lugar bajo la afirmación plena de sus derechos como productor. Por lo tanto, las universidades que nacen del desmembramiento de la Universidad de Chile empujan por la recuperación plena del ejercicio de sus derechos y del conjunto de los productores nacionalmente agrupados. Será de su nueva condición como sujeto privado que las universidades, en la unidad de sus estamentos, se vuelven un bastión de la lucha democrática junto al resto de la clase obrera también movilizada en la segunda mitad de los '80 contra la dictadura.

La recuperación económica que arranca a mitad de los '80 impulsa a la clase obrera a la lucha por el restablecimiento de la reproducción normal de sus atributos políticos en alianza con otros sectores que están reprimidos por el régimen militar. En 1987 los estudiantes tomarán lugar en este proceso, fundamentalmente como

B ANUARI DEL CONFLICTE SOCIAL, 12

DOI. 10.1344/ACS ACS 2021.12.12 
paladines de las libertades democráticas. Retoman las banderas de la reforma universitaria y demandan la democratización de la universidad, prefigurando la crisis política del régimen que cae, sobre el peso de su propia expansión, en el plebiscito de 1988. Sin embargo, este triunfo político no detendrá la transformación que ya estaba en curso. Si bien la conciencia nacional anterior sigue siendo la preponderante en el movimiento estudiantil en lucha contra la dictadura, sólo lo hace formalmente. La conciencia nacional empezará a dar un giro hacia "el interior" de la universidad y se expande como una conciencia gremial en defensa de la educación pública. Esta aparece cada vez más amenazada por la proliferación de competidores que nacen de la expansión de la formación universitaria traccionada por la demanda de obreros calificados. Perdiendo el carácter oligopólico, la competencia le pone por delante su propia reproducción inmediata pero ahora acotada a diferentes direcciones. Tendremos, por un lado, el movimiento estudiantil -que de ahora en adelante denominaremos "tradicional"- que sigue vinculado por medio de la fuente de financiamiento de sus respectivas casas de estudio al Estado. Por otro lado, tendremos a los estudiantes de universidades privadas. En su unidad inmediata, cada uno de estos fragmentos es competidor del otro. Esta doble determinación es el punto a partir del cual el movimiento estudiantil desarrollará formas de dirección y acción política, diferentes del movimiento estudiantil del ciclo anterior. Cambiando su vida práctica, vive su práctica de un modo diferente.

Entre 1986 y 1998, los obreros ocupados con educación superior o terciaria se expanden a un promedio del $9 \%$ anual. Pasan de ser el $16 \%$ de la fuerza de trabajo ocupada a representar el $28 \%$. Como proceso supuesto en el anterior, la matrícula universitaria se expande. Teniendo a la base el ciclo expansivo 1984-1998, tal como señalamos, la demanda de obreros calificados es cubierta con población de los deciles de mayores ingresos (Orellana, 2011). El aumento del erario 
fiscal permite que en los ' 90 se lleve adelante la centralización de un crédito especial (el Aporte Fiscal Directo) ${ }^{23}$ que, si bien aumenta en términos absolutos, no lo hace igual en términos relativos al ingreso de los estudiantes (Kremerman, 2005). Esto empuja al movimiento estudiantil a abandonar progresivamente su conciencia inmediatamente nacionalista y fortalece su actividad gremial. Se comienza a imponer entonces una conciencia político gremial que -sin presentarse como tal de manera plena- le da el lugar a la izquierda que quedará excluida del proceso democrático previo, dentro de la cual se encuentra una revitalizada línea "apartidista" que formará a las nuevas camadas de dirigentes estudiantiles en los 90 y los 2000. Crece, sobre todo en la $\mathrm{UCH}$, el último partido de los estudiantes clásicos: el PC.

El modo específico de financiamiento por parte del Estado determinó la salida de los partidos de gobierno de gran parte de las direcciones estudiantiles y el arribo de su oposición. El movimiento estudiantil movilizado junto a una larga tradición de militantes, la herencia de la producción ideológica de la generación anterior y vinculado al Estado vía financiamiento directo, se convierte en "modelo" de lucha para otras organizaciones que se desarrollarán después. Es así que, en los primeros años de los '90, el proceso de producción de la nueva dirección estudiantil aparece como un quiebre radical con las viejas direcciones y destruye, literalmente, las federaciones (Meza, 2006; Thielemann, 2016). Además del PC, crecen quienes ya a fines de los '80 se presentan como oposición por

23 "El Aporte Fiscal Directo (AFD) es el instrumento de financiamiento más importante del Estado para las Universidades pertenecientes al Consejo de Rectores de Universidades Chilenas (CRUCH). Este financiamiento es adicional al Aporte Fiscal Indirecto (AFI), el cual se distribuye en función a la matrícula de los alumnos de primer año con los mejores puntajes en la Prueba de Selección Universitaria (PSU), y está dirigido a todas las instituciones de educación superior y no sólo a las pertenecientes al CRUCH" (Ramírez y Alfaro, 2012: 28). 
izquierda al modo bajo el cual se recuperan las condiciones democráticas personificadas por la Concertación de Partidos por la Democracia (CPD). ${ }^{24}$

Después del quiebre de las federaciones en los primeros años de los '90, los estudiantes que se incorporan a la educación superior tradicional desarrollan una conciencia política diferente. Una conciencia opuesta a los partidos políticos tradicionales que les permite disputar el gasto social y ampliar los fondos dirigidos al financiamiento directo de las universidades tradicionales a medida que crecen las matrículas y suben los aranceles. El conflicto aparece en oposición a la expansión de la educación superior privada que crece en aparente desmedro de las universidades del Estado. Producto de la competencia, el movimiento estudiantil nacional se atrinchera bajo la defensa acérrima de la educación pública y en contra de las políticas neoliberales. Este proceso sentará las bases para un lenguaje interior por medio del cual se generaliza la crítica a la producción "mercantil" de la educación en todos sus niveles. Más adelante, esta misma oposición a la mercantilización (de la vida en general) será el faro para el conjunto del movimiento que media la apropiación del gasto social enfrentado al capital privado y al Estado. La lucha contra la asignación por parte del mercado se volverá el modo ideal en el cual la dirección estudiantil se refiere a sí misma a la hora de organizar la acción política del movimiento estudiantil.

Como mencionamos, esta nueva conciencia política de izquierda brota de los sectores que ya a fines de los ' 80 se presentan como oposición. Al reconocer en "la Concertación” a los gestores y promotores de las ideas que socavan las viejas formas de reproducir a

${ }^{24}$ La CPD estaba compuesta por la DC, el Partido por la Democracia (PPD), el PS y el PRSD.

B ANUARI DEL CONFLICTE SOCIAL, 12

DOI. 10.1344/ACS ACS 2021.12.12 
la clase obrera, se levantan en oposición. En un primer empuje, el PC se yergue como la dirección preferencial. Pero la misma conciencia gremial que se fortalece en lucha contra el mercado impulsado como política de Estado, choca con las pretensiones del PC por intentar avanzar en la gestión directa del mismo. El refuerzo de la conciencia gremial de los estudiantes fortalece un lenguaje interior que toma forma como uno que traduce su propia acción como "apartidista" frente a los partidos. "Lo social" se opone a "lo político". ${ }^{25}$ Madurado este trasfondo en la crítica al partido político que bebe de la cultura "punk" y del "hip hop" (Thielemann, 2016), los estudiantes que conforman el nuevo personal político del movimiento afirman su acción bajo formas ideológicas de "democracia radical" en oposición a las formas de organización del Estado y a las organizaciones partidarias con pretensiones estatales. Sobre la tierra fértil que dejan los colectivos estudiantiles independientes de los ' 90 , brota una primera generación sobre la cual enraízan las ideas de la nueva izquierda (Thielemann, 2016). Dentro del conjunto de visiones nacionales, afirmadas contra el Estado, volviendo de la negra noche de la memoria, el anarquismo florece en el nuevo lenguaje interior del movimiento estudiantil como uno de sus dialectos específicos en el ciclo expansivo que prosigue al 2004 (Quiroga, 2005).

Un alza del precio del cobre a partir de la mitad de la primera década del siglo XXI genera una nueva expansión de la acumulación

${ }^{25}$ El epítome de esa disociación que pierde de vista la especificidad de lo político organizado como Estado, ergo, como partido político, y limita la acción política general de clase a la política gremial está expresada en los modos en que el anarquismo de fines de siglo XX y principios del XXI en Chile concebía su propia acción política Distinguía entonces entre organizaciones políticas y organizaciones político sociales, contradicción que, a la larga, se choca con cualquier acción centralizada. Si bien no existe un trabajo sistemático sobre los supuestos de las distinciones imaginadas por el anarquismo de los años ‘90 y 2000 sobre su propia práctica, se puede consultar los trabajos de Ramírez (2013) y Quiroga (2005). 
de capital en Chile profundizando el proceso de diferenciación de la clase obrera. El aumento del ingreso fiscal y la política del "crecer con igualdad" del "laguismo" 26 concertacionista democratizan el acceso al crédito fiscal y ponen al Estado como aval, dando paso a la producción de fuerza de trabajo calificada a partir del acceso de deciles inferiores respecto de los sirven de base para los años '80 y ' 90 (Orellana, 2011). El nuevo Crédito con Aval del Estado (CAE) ${ }^{27}$ dará curso a un proceso de producción de fuerza de trabajo calificada en base al endeudamiento familiar subsidiado. La matrícula en educación superior crece a una tasa del 10\% anual entre 2006 y 2011. Si bien no se trata de un derecho universal, se generaliza en un nuevo grado la relación específica del Estado con amplias porciones de familias obreras, ahora atadas a la deuda mediada por los bancos o por las universidades privadas (Espinoza y González, 2016). Es decir, el subsidio deja de ser un subsidio directo al conjunto del capital de modo indistinto al ser producida la fuerza de trabajo directamente por el Estado y luego consumido por el capital nacional. Ahora, su producción está mediada por la acción privada de una serie de capitales que se reproducen a partir de los ingresos de la familia obrera, por un lado, y el subsidio estatal por otro. De esta forma pagan el trabajo de obrero colectivo que educa a la nueva fuerza de trabajo, por un lado y forman la ganancia del capitalista, por otro. Esto cambia la apariencia en que el capitalista general -el Estado- participa en la producción social total, que pasa de ser directa a indirecta, pero sin cambiar su naturaleza: sostener la valorización del conjunto del capital individual. Pero el CAE, tendrá una diferencia específica respecto de

26 En alusión a Ricardo Lagos, presidente de Chile entre 2000 y 2006.

${ }^{27}$ Establecido mediante la ley nro. 20.027 que consiste en la entrega de un crédito otorgado por el sistema financiero a las instituciones de educación superior cuyo aval corre a cuenta del Estado.

\section{๑}


los créditos de los '90 que hace que las movilizaciones estudiantiles de 2006, 2008 y 2011 se parecieran más entre sí, por su transversalidad, que en 1990 y el 2001 (Sotomayor, 2019). Ahora todas las universidades disputan en igualdad el financiamiento a través del conjunto del movimiento estudiantil que puede superar la diferencia entre educación "pública" y "privada". Pero esta igualación, como veremos, no es sólo "económica", sino que, realizada como tal, toma la forma de un giro en el modo en que la conciencia del sujeto estudiantil se refiere a sí mismo.

Desaparecida la diferencia que en los '90 los mantuvo separados y que generaba la apariencia de un movimiento social aparentemente "anómalo" (Thielemann, 2016), la solidaridad de la lucha se expande. El aumento del gasto estatal pone al estudiantado y a sus familias en una relación contradictoria más amplia, ahora unida por el principal garante de la deuda: el Estado. Por medio de una relación económica, la clase obrera ve atada su reproducción y elabora un discurso común sobre la especificidad de la misma. A diferencia del privado, el Estado aparece como un único acreedor, como el capitalista general. La expansión y el cambio en la forma de financiamiento amplía la base del conjunto de "partidos estudiantiles". Si bien por un lado se consolida la Izquierda Autónoma como fuerza política, también crecen los anarquistas con el Frente de Estudiantes Libertarios (FEL) y la herencia mirista con el Fuerza Universitaria Rebelde (FUR). Finalmente, con el paso del PC a Nueva Mayoría, y el afianzamiento de la conducción autonomista, varias organizaciones apartidistas dispersas forman la Unión Nacional de Estudiantes (UNE) en 2011. Este año se impone el movimiento estudiantil con una masividad inédita y la unidad programática de las direcciones estudiantiles de izquierda se consolidan como "antineoliberales". Es decir, como sujetos que conciben a su propia acción política como un modo de intervenir en el curso del mercado y a la acción estatal como 
la forma más potente de lo mismo. La lucha por el gasto social aparece inmediatamente ya no como un atributo de los partidos obreros, sino como una lucha directa con él por el financiamiento. Limitada a dirigir, mas no a determinar (Thao, 1971), una porción de trabajo social dentro del proceso de transformaciones, el "antineoliberalismo" se consolida como el nuevo lenguaje interior de los estudiantes en donde se señala a sí mismo como el modo de contraponer la acción estatal directa al funcionamiento automático del mercado.

Aunque no se realice plenamente, la lucha "antineoliberal", como el telón de fondo sobre el cual tiene sentido la lucha por la gestión del financiamiento, se generaliza como el modo en que la clase obrera le impondrá las condiciones generales de producción al capital nacional El "antineoliberalismo" es la expresión parcial de la conciencia estatal del productor privado que impone la misma necesidad general en oposición a él, como si viniera "por fuera" del Estado. Tal cual aparentaba a principios de siglo. El interés "general" o "social" ya no parece estar portado inmediatamente en el Estado, sino que, mediado por la conciencia "antineoliberal", la acción del movimiento estudiantil se indica como la intervención directa de la política pública. Es por medio de la acción política independiente del movimiento estudiantil universitario, enfrentado a la gestión directa del Estado, que este le impone, finalmente, las condiciones generales de su propia reproducción. Luego, puesto en su propio lenguaje interior como conciencia de "lo público" contrapuesto a "lo mercantil", las direcciones estudiantiles universitarias serán la base sobre la cual, en un nuevo ciclo de contracción de la renta de la tierra, se imponga una gestión proclive a la intervención estatal directa para mediar la crisis no resuelta que deja la contracción de la economía mundial en curso. Pero ya no como "socialistas" sino como portadores de una "nueva democracia”. Si en el ciclo anterior la nueva izquierda era más 
socialista que la vieja tradición socialista y comunista, ahora será más democrática que los demócratas de turno.

\section{Conclusiones}

Hicimos un recorrido por la historia de la dirección del movimiento estudiantil que no está explicada exclusivamente a partir de una sistematización de sus "discursos" sobre su propia acción. También intentamos ir más allá de quienes ven una diferencia en la reproducción de la clase obrera pero no logran poner la unidad de ese proceso y presentan de forma desarticulada elementos parciales que aquí intentamos reponer en la riqueza de su desarrollo.

Buscando explicar la unidad de las distintas formas de la conciencia política del movimiento estudiantil intentamos mostrar cómo ésta es forma concreta de una relación indirecta que la determina. Vimos que esta especificidad brota del carácter privado del trabajo social organizado mundialmente. Este produce, dentro del espacio nacional, un determinado "lenguaje interior" por medio del cual el estudiantado, mediado por sus direcciones -reconocidas o nose identifica como un actor político y sujeto histórico. Es decir, intentamos mostrar cómo la vida práctica del movimiento estudiantil es la que determina, finalmente, la forma de su conciencia política.

A lo largo de tres grandes ciclos económicos determinados por los flujos de renta diferencial de la tierra y mediados por intensas luchas de clases, intentamos mostrar por qué el sector de la clase obrera calificada en formación se vincula con el resto de la clase obrera ligada a una formación en el oficio y se vuelve anarquista después de ser radical. Luego, presentamos cómo el período de entreguerras y la posguerra le imponen una conciencia nacional, que la empuja a formar partidos y continuar, en unidad directa con ella, los combates propios de su reproducción. Mostramos cómo más tarde se le impone una conciencia "antineoliberal", que no se identifica mayoritariamente con 
el nacionalismo o los partidos nacionales a pesar de no dejar de ser nacional. Lo hace, en cambio, con la democracia radicalizada, la que presenta como "verdadera" e implementaría en sus propias formas de organización. Vimos cómo estos métodos personificados por la conciencia autonomista -en un sentido genérico- se vuelven la base para la expansión del vínculo solidario fortalecido por la creciente intervención estatal directa. El nuevo "movimiento social", liderado por la conciencia antineoliberal, parece empujar la frontera de la propiedad pública (ya sea estatal o "comunitaria") sobre la privada. Mostramos que, luego de una reaparición como la versión más radical del "apartidismo", el anarquismo da paso a una nueva conciencia política que empieza tomando cuerpo en una serie de organizaciones estudiantiles que, finalmente, decantaron en nuevos partidos de clase obrera. Esta nueva forma de la conciencia política crece en el marco de una profunda crisis que encuentra su principal determinación en un nuevo ciclo de contracción de la renta de la tierra. Si bien, por falta de espacio, no desarrollamos esta forma más actual, pudimos mostrar cómo era una determinación propia del proceso de regeneración del personal político hoy en curso. Es un elemento sobre el que se debería profundizar si se quiere avanzar en el conocimiento de la naturaleza de la acción política de la clase obrera en sus diferentes expresiones. Y es que, como dice Engels, mientras nos resistamos obstinadamente a comprender la naturaleza y el carácter de nuestra propia relación social, estas fuerzas actuarán a pesar de nosotros, contra nosotros, y nos dominarán (Engels, 1952). 


\section{Referencias bibliográficas}

Abramo, L. (2004). Inserción laboral de las mujeres en América Latina: ¿una fuerza de trabajo secundaria? Revista Estudios Feministas, 12 (2), http://dx.doi.org/10.1590/S0104-026X2004000200013

Ahumada, M. (2019). Political Economy of Peripheral Growth. Springer International Publishing.

Agacino, R. (2013). Movilizaciones estudiantiles en Chile: Anticipando el futuro. Educação em revista, 14(1), pp. 7-20. https://doi.org/10.36311/2236-5192.2013.v14n1.3294

Altvater, E. (1976). Estado y capitalismo. Notas sobre algunos problemas del intervencionismo estatal. Cuadernos políticos, 9, 9-30.

Backhaus, H. (1978). La dialéctica de la forma de valor. Dialéctica, 4, 934.

Barría, D. (2015). Empleados públicos y clase media, Chile 1880-1920: Un análisis exploratorio a partir de cifras oficiales. Revista de Historia y Geografía, 32, 77-100.

https://doi.org/10.29344/07194145.32.1261

Barrera, M. (1968). Trayectoria del movimiento de reforma universitaria en Chile. Journal of Inter-American Studies, 10(4), 617-636. https://doi.org/10.2307/165320

Bastías, I. (2007). Movimientos populares (Siglos XIX-XX): Política libertaria $y$ movimiento anarquista en Santiago. [Informe de Seminario para optar al grado de Licenciado en Historia]. Facultad de Filosofía y Humanidades. Departamento de Ciencias Históricas.

Universidad de Chile.

https://repositorio.uchile.cl/handle/2250/110434

B ANUARI DEL CONFLICTE SOCIAL, 12

DOI. 10.1344/ACS ACS 2021.12.12 
Braghetto, M. (2013). El movimiento universitario y las transformaciones de la educación superior en el Chile neoliberal. Irquierdas 16, 55-74.

Caligaris, G. (2014). Dos debates en torno a la renta de la tierra y sus implicancias para el análisis de la acumulación de capital en la Argentina. Razón y Revolución, 27, 59-79.

Canales, A. (2018). Nueva era de las migraciones en Chile. De la diferenciación migratoria a la desigualdad social. En R. Baeninger. et al. (Ed.), Migrações Sul-Sul (pp. 37-53). Campinas: Núcleo de Estudos de População "Elza Berquó"Nepo/Unicamp.

Cañas, E. (2016). Movimiento estudiantil en Chile 2011: Causas y Características. Revista de Historia y Geografía, 34, 109-34. https://doi.org/10.29344/07194145.34.357

Cariola, C. y Sunkel, O. (1982). Un siglo de historia económica de Chile: 1830-1930: Dos ensayos y una bibliografía. Ediciones Cultura Hispánica del Instituto de Cooperación Iberoamericana.

Dachevsky, F. (2021). El capital y la nación desde la crítica de la economía política. Revista Izquierdas, 50, 1-21.

Duménil, G., \& Lévy, D. (2002). The profit rate: where and how much did it fall? Did it recover? (USA 1948-2000). Review of Radical Political Economics, 34(4), 437-461.

De la Cuadra, F. (2008) Movimiento estudiantil en Chile: Lucha, participación y democracia. Revista Electrónica Sintesis 2.

De Vroey, M. (1988). La teoría marxista del valor: balance crítico de los debates recientes. Lecturas de economía, 27, 73-110.

Donoso, S. (2014). La Reconstrucción de La Acción Colectiva En El Chile Post-Transición: El Caso Del Movimiento Estudiantil. Documento de 
Trabajo. Clacso.

http://biblioteca.clacso.edu.ar/clacso/becas/20140905014946/ Donoso_Informe_Sep_2014.pdf.

Donoso, A. (2020). Movimiento estudiantil chileno de 2011 y la lógica educacional detrás de su crítica al neoliberalismo. Educaşão e Pesquisa 46. https://doi.org/10.1590/S1678-4634202046

Engels, F. (1952). Del socialismo utópico al socialismo científico En Marx, K y Engels, F. Obras escogidas en dos tomos. (pp. 84-144). Ediciones en lenguas extranjeras.

Espinoza, O., y González, L. (2016). La educación superior en Chile y la compleja transición desde el régimen de autofinanciamiento hacia el régimen de gratuidad. Revista Latinoamericana de Educación Comparada, 7 (10), 35-51.Fleet, N. (2011). Movimiento estudiantil y transformaciones sociales en Chile: una perspectiva sociológica. Polis. Revista Latinoamericana, 10 (30), 99-116.

Ffrench-Davis, R. (2018). Reformas económicas en Chile 1973-2017. Taurus.

Gárate, M. (2012). La revolución capitalista en Chile. Desde la tradición del liberalismo decimonónico (1810-1970) a la búsqueda de una utopia neoconservadora (1973-2003). Ediciones Universidad Alberto Hurtado.

Garcés, M. (2013). El movimiento estudiantil y la crisis de legitimidad de la política chilena. Pensar Historia, 2, 83-93.

Garcés, M. (2002). Tomando su sitio: el movimiento de pobladores de Santiago, 1957-1970. Lom ediciones.

Garretón, M., Cruz, M., Aguirre, F., Bro, N., Farías, E., Ferreti, P., y Ramos, T. (2011). Movimiento social, nuevas formas de hacer política y enclaves autoritarios. Polis 10(30), 117-40. http://dx.doi.org/10.4067/S0718-65682011000300006 
Garretón, M., y Martínez, J. (1985). El Movimiento Estudiantil: Conceptos e Historia. Ediciones Sur.

Gatica, J. (2019). Deindustrialization in Chile. Westview Press.

Grez, S. (2007). Los Anarquistas y El Movimiento Obrero. La Alborada de "La Idea" En Chile. Lom ediciones.

Gunder Frank, A. (1968). Chile: El Desarrollo Del Subdesarrollo. Monthly Review.

Hirsch, M., y Iñigo, L. (2005). La formación del sistema educativo argentino: ¿producción de fuerza de trabajo vs. producción de ciudadanos? [Ponencia presentada]. 7o Congreso Nacional de Estudios del Trabajo, Facultad de Ciencias Económicas, Universidad de Buenos Aires.

Iñigo Carrera, J. (1997). De la simple mercancía a la mercancía-capital: La transformación de los valores en precios de producción. Documento de Investigación del Centro para la Investigación como Crítica Práctica. https://cicpint.org/es/2591-2/

Iñigo Carrera, J. (2007). Conocer el capital hoy. Usar críticamente El Capital. Imago Mundi.

Iñigo Carrera, J. (2013). Ser social y producción de conciencia:

Economistas para qué. [Ponencia presentada]. II Jornadas de Pensamiento Crítico Latinoamericano/Seminario Internacional REDEM-SEPLA, Universidad Nacional de Río Cuarto.

Iñigo Carrera, J. (2013a). El Capital: razón histórica, sujeto revolucionario y conciencia. Imago Mundi.

Iñigo Carrera, J. (2017). La Renta de La Tierra. Formas, Fuentes y Apropiación. Imago Mundi.

Jadresic, E. (1990). Salarios en el largo plazo: Chile 1960-1989. Colección estudios CIEPLAN, 29, 9-34.

Kautsky, K. (1979). El camino del poder. Fontamara.

\section{B}


Kay, C. (1998). La cuestión agraria y el campesinado en Chile hoy. Debate Agrario, 27, 79-110.

Kremerman, M., y Páez, A. (2016). Endeudar Para Gobernar y Mercantilizar: El Caso Del CAE. Fundación Sol. https://www.fundacionsol.cl/cl_luzit_herramientas/static/wpcontent/uploads/2016/08/Estudio-CAE-20163-1.pdf.

Kremerman, M. (2005). Crisis en el Sistema de Educación Superior en Chile: Análisis y propuestas. Santiago de Chile. Documento de trabajo, Fundación Terram. www.terram.cl/docs/Rpp17_educacion.pdf

Kurz, R. (2016). El colapso de la modernización. Marat.

Laclau, E., y Mouffe, C. (1987). Hegemonía y estrategia socialista. Hacia una radicalización de la democracia. Siglo XXI editores.

Lagos, R. (1966). La Industria En Chile. Antecedentes Estructurales. Universidad de Chile, Instituto de Economía.

Lenin, V. (1969). Contenido económico del populismo y su crítica en el libro del señor Struve. En B. Lenin, Obras completas, tomo I (pp. 351-525). Editorial Cartago.

Lozoya, I. (2020). Intelectuales y revolución: Cientificos sociales latinoamericanos en el MIR chileno (1965-1973). Ariadna Ediciones.

Lüders R.; Díaz, J.; y Wagner, G. (2016). La república en cifras: Historical statistics. Ediciones UC.

Lukács, G. (2013). Historia y conciencia de clase. Ediciones ryr.

Marini, R. (1979). El ciclo del capital en la economía dependiente. En U. Oswald, (coord.). Mercado y dependencia (pp. 37-55). Nueva Imagen.

Marx, K. (2011). Contribución a la crítica de la economía política. Siglo XXI Editores. 
Marx, K. (2009) El Capital. Libro primero: el proceso de producción del capital. Vol. 2. Siglo XXI editores.

Marx, K. (2009a). El Capital. Libro tercero: el proceso global de la producción capitalista. Siglo XXI editores

Marx, K., y Engels, F. (1968). La ideología alemana: crítica de la novísima filosofía alemana en las personas de sus representantes Feuerbach, B. Bauer y Stirnery del socialismo alemán en las de sus diferentes profetas. Ediciones Pueblos Unidos.

Marx, K., y Engels, F. (1973). El Capital. Vol. III. El proceso de la producción capitalista en su conjunto. Fondo de Cultura Económica.

Marx, K., y Engels, F. (2012). Manifiesto del Partido Comunista. En J. Muñoz, Obra selecta. Antología de textos de economía y de filosofía. Manuscritos de París. Manifiesto del Partido Comunista. Crítica del programa de Gotha. Editorial Gredos

Meller, P. (1996). Un siglo de economía politica chilena (1890-1990). Editorial Andrés Bello.

Meza, A. (2006). Un tropezón no es caída. Historia del Movimiento Estudiantil en la Universidad de Concepción (1990-2000). En K.Alfaro et al., Historia sociopolitica del Concepción Contemporáneo. Memoria, identidad y territorio (pp. 199-256). Ediciones Escaparate/ U ARCIS.

Milos, P. (2007). Historia y memoria: 2 de abril de 1957. Lom ediciones.

Moguillansky, G. (1999). La Inversión En Chile: ¿El Fin de Un Ciclo de Expansión? Fondo de Cultura Económica.

Moraga, F. (2006). Crisis y Recomposición Del Movimiento Estudiantil Chileno (1990-2001). En R. Marsiske (coordinador), Movimientos estudiantiles en la historia de América Latina III (pp. 179-252). CESU-UNAM/Plaza y Valdés ed.

\section{B ANUARI DEL CONFLICTE SOCIAL, 12}


Moraga, F. (2012). El Congreso de Estudiantes Latinoamericanos de Santiago. Antimperialismo e Indoamericanismo en el movimiento estudiantil chileno (1935-1940), Historia Crítica, 47, 187-213.

Muñoz, V., y Durán, C. (2019). Los jóvenes, la política y los movimientos estudiantiles en el Chile reciente. Ciclos sociopolíticos entre 1967 y 2017. Revista Izquierdas, 45, 129-59. http://dx.doi.org/10.4067/S0718-50492019000100129

Narbona, K. (2015). Antecedentes Del Modelo de Relaciones Laborales Chileno, Documento de trabajo, Fundación Sol. https://www.researchgate.net/publication/299404533_Anteced entes_del_Modelo_de_Relaciones_Laborales_Chileno.

Neghme, F., y Leiva, S. (2000). La Política Del Movimiento de Izquierda Revolucionaria (MIR) Durante La Unidad Popular y Su Influencia Sobre Los Obreros y Pobladores de Santiago. [Tesis para optar al grado de licenciado en educación en historia y geografía, Universidad de Santiago de Chile].

http://www.archivochile.cl/Ideas_Autores/leivas/leivas0005.pd $\mathrm{f}$

Orellana, V. (2011). Nuevos y viejos profesionales en Chile. Impacto de la educación superior en la estructura social (1983 - 2010) elementos para una interpretación sociológica. [Tesis de licenciado en Sociología, Universidad de Chile].

http://www.tesis.uchile.cl/tesis/uchile/2011/csorellana_v/html/index.html

Ortega, L. (2005). Chile en ruta al capitalismo: Cambio, euforia y depresión 1850-1880. Lom ediciones.

Ortega, L. (1991). El proceso de industrialización en Chile 1850- 1930. Revista Historia, 26(21), 213-46. 
Oyarzún, L. (2012). Desarrollo es acceso a la educación: Las movilizaciones estudiantiles en Chile. Anuario CEIPAZ, 5, 221234.

Plejanov, G. (1964). El papel del individuo en la historia (pp. 427-463). En Plejanov, Obras escogidas, tomo I. Editorial Quetzal.

Postone, M. (2006). Tiempo, trabajo y dominación social: una reinterpretación de la teoría crítica de Marx. Marcial Pons.

Quiroga, P. (2005). Movimiento populares, siglos XIX y XX. La diversidad anarquista: Santiago, 1990-2005. [Informe de Seminario para optar al grado de Licenciado en Historia]. Santiago, Chile: Universidad de Chile - Facultad de Filosofía y Humanidades. http://repositorio.uchile.cl/handle/2250/110219

Ramírez, P., y Alfaro, J. (2012). Desincentivo a la Investigación: Resultado del Comportamiento Inequitativo del Modelo de Aporte Fiscal Directo (AFD) a las Universidades Chilenas. Formación Universitaria, 5(4), 27-36.

Reyes, N. (2015). Salarios agrícolas durante la industrialización en Chile: Factores económicos e institucionales. Estudios de Economía, 42(2), 121-141.

Reyes, E. (1994). Salitre de Chile Apertura Inversión y Mercado Mundial. Documento de Trabajo, Serie de investigaciones $\mathrm{N}^{\circ} 6$, Dirección de Investigaciones. Universidad Católica Blas Cañas.

Rifo, M. (2013). Movimiento estudiantil, sistema educativo y crisis política actual en Chile. Polis. Revista Latinoamericana, 36. http://dx.doi.org/10.4067/S0718-65682013000300010

Rivas, G., y Kornblihtt, J. (2017, septiembre). Notas preliminares sobre la magnitud de la renta de la tierra minera y su apropiación en Chile (1997-2012). [Presentación de ponencia]. X Jornadas de Economía Crítica (JEC), Buenos Aires. 
Rivas, G., y Casique, M. (2021). Marini y la economía política marxista de la dependencia. Una aproximación crítica a partir de su análisis del proceso chileno. Revista Izquierdas, 50, 1-26.

Robles Báez, M. (2014). Dialéctica y capital. Elementos para una reconstrucción de la crítica de la economía política. Ediciones ryr.

Rojas, J. (2004). Los trabajadores chilenos, desde la colonia hasta 1973. CEME.

Rubilar, L. (2011). Para comprender el movimiento estudiantil en Chile. Educere, 15(52), 581-588.

Rubin, I. (1990). Essays on Marx's Theory of Value. Black Rose Books

Ruiz, C., y Boccardo, G. (2015). Los chilenos bajo el neoliberalismo. Ediciones y Publicaciones El Buen Aire S.A.

Salazar, G. (2003). Historia de la acumulación capitalista en Chile. Lom Ediciones.

Salazar, G. (2006). La violencia politica popular en las" Grandes Alamedas: La violencia en Chile, 1947-1987: Una perspectiva histórico-popular. Lom ediciones.

Salazar, G. (2009). Del Poder Constituyente de Asalariados e Intelectuales (Chile, siglos XX y XXI). Lom Ediciones.

Sanhueza, J. (1997). La Confederación General de Trabajadores y el anarquismo chileno de los años 30. Historia, 30, 313-382.

Seiffer, T., y Rivas, G. (2017). La política social como forma de reproducción de la especificidad histórica de la acumulación de capital en Argentina (2003-2016). Estudios del Trabajo; 54; 91-117.

Silva, P. (2012). Tecnócratas y política en Chile: de los Chicago Boys a los Monjes de Cieplan. En T. Ariztía (Ed), Produciendo lo social: Usos de las ciencias sociales en el Chile reciente (pp. 73-100). Ediciones Universidad Diego Portales. 
Sohn-Rethel, A. (2017). Trabajo manual y trabajo intelectual. Una crítica de la epistemología. Dado Ediciones.

Sotomayor, F. I. (2019). Malestar, acción colectiva y movimientos sociales en chile:(2001-2017). Revista Ciência \& Saberes-UniFacema, 4(2), 1137-1151.

Starosta, G., y Steimberg, R. (2019). El desarrollo capitalista latinoamericano desde la crítica de la economía política. En O. Cavero (Ed.), El poder de las preguntas. Ensayos desde Marx sobre el Perú y el mundo contemporáneo (pp. 161-216). UCH Fondo Editorial.

Stefoni, C. (2005). Migración en Chile. Colección ideas, 6(59), 1-27.

Sunkel, O., y Paz, P. (1970). El Subdesarrollo Latinoamericano y La Teoría Del Desarrollo. Siglo veintiuno editores.

Thao, T.D. (1971). Fenomenología y materialismo dialéctico. Ediciones Nueva Visión.

Thao, T.D. (2020). Investigaciones sobre el origen del lenguaje y la conciencia. Critical \& Transdisciplinary Editions.

Thielemann, L. (2016). La Anomalia Social de La Transición. Movimiento Estudiantil e Izquierda Universitaria En El Chile de Los Noventa (1987 - 2000). Tiempo robado.

Undurraga, T. (2011) Rearticulación de grupos económicos y renovación ideológica del empresariado en Chile 1975 - 2012: La paradoja de la concentración. En M. Monsalve. (Ed.), Grupos económicos y mediana empresa familiar en América Latina (pp. 11-39). Universidad del Pacífico.

Valenzuela, H. (2008). Historia Del Movimiento Obrero Chileno. Quimantú. Zepeda, R. (2014). El movimiento estudiantil chileno. Revista de Sociología de la Educación-RASE, 7(3), 689-695. 
Zizek, S. (2003). Ideología: un mapa de la cuestión. Fondo de Cultura Económica.

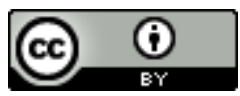

Este texto está protegido por una licencia Reconocimiento Creative Commons 4.0.

Usted es libre para Compartir — copiar y redistribuir el material en cualquier medio o formato- $-\mathrm{y}$ Adaptar el documento — remezclar, transformar y crear a partir del material — para cualquier propósito, incluso comercialmente, siempre que cumpla la condición de:

Atribución: Usted debe reconocer el crédito de una obra de manera adecuada, proporcionar un enlace a la licencia, e indicar si se han realizado cambios. Puede hacerlo en cualquier forma razonable, pero no de forma tal que sugiera que tiene el apoyo del licenciante o lo recibe por el uso que hace. 